\title{
Sliding Mode Real-Time Control of Photovoltaic Systems Using Neural Estimators
}

\author{
J. A. Ramos-Hernanz, ${ }^{1}$ O. Barambones, ${ }^{2}$ J. M. Lopez-Guede, ${ }^{2}$ \\ I. Zamora, ${ }^{3}$ P. Eguia, ${ }^{3}$ and M. Farhat ${ }^{4}$ \\ ${ }^{1}$ Electrical Engineering Department, Faculty of Engineering Vitoria-Gasteiz, University of the Basque Country, \\ Nieves Cano 12, 01006 Vitoria-Gasteiz, Spain \\ ${ }^{2}$ Systems Engineering and Automatic Control Department, Faculty of Engineering Vitoria-Gasteiz, University of the Basque Country, \\ Nieves Cano 12, 01006 Vitoria-Gasteiz, Spain \\ ${ }^{3}$ Electrical Engineering Department, Faculty of Engineering, University of the Basque Country, Alameda Urquijo, s/n, \\ 48013 Bilbao, Spain \\ ${ }^{4}$ Department of Electrical, Electronics and Communications Engineering, American University of Ras Al Khaimah, \\ Sheikh Saqr Bin Khalid Rd., Ras Al Khaimah, UAE
}

Correspondence should be addressed to J. A. Ramos-Hernanz; josean.ramos@ehu.es

Received 15 April 2016; Revised 13 June 2016; Accepted 28 June 2016

Academic Editor: Prakash Basnyat

Copyright (C) 2016 J. A. Ramos-Hernanz et al. This is an open access article distributed under the Creative Commons Attribution License, which permits unrestricted use, distribution, and reproduction in any medium, provided the original work is properly cited.

The maximum power point tracking (MPPT) problem has attracted the attention of many researchers, because it is convenient to obtain the maximum power of a photovoltaic module regardless of the weather conditions and the load. In this paper, a novel control for a boost DC/DC converter has been introduced. It is based on a sliding mode controller (SMC) that takes a current signal as reference instead of a voltage, which is generated by a neuronal reference current generator. That reference current indicates the current $\left(I_{\mathrm{MPP}}\right)$ at the maximum power point (MPP) for given weather conditions. In order to test the designed control system, a photovoltaic module model based on a second artificial neuronal network (ANN) has been obtained from experimental data gathered during 18 months in the Faculty of Engineering Vitoria-Gasteiz (Spain). We have analyzed the performance of such model and we found that it is very accurate (MSE $=0.062 \mathrm{~A}$ and $R=0.991$ with test dataset). We also have tested the performance of the overall SMC design with both simulated and real tests, concluding that it guarantees that the power in the output of the converter is very close to the power of the photovoltaic module output.

\section{Introduction}

In the recent Paris Conference [1], we can find important initiatives for supporting green energies. With regard to photovoltaic energy, two main initiatives stand out: the former, the creation of the "Alliance for Solar Energy" promoted by the Government of India and signed by 120 countries, and the latter, the creation of the "Global Solar Council," mainly composed by associations devoted to renewable and solar energy from the five continents. The council was created with the aim of promoting photovoltaic energy worldwide through a unique interlocutor of the sector with the international organizations, increasing collaboration between different countries and supporting emerging solar markets.

Due to its simplicity of operation, robustness, and cheapness, photovoltaic solar energy is a very appropriate source of energy, especially for emerging countries, where the construction of large electrical infrastructures is infeasible in some areas. Moreover, in recent years, great progress in this area, better efficiency, and improved performance of photovoltaic modules have been achieved. These factors, along with the advancement of electronic technology, make this type of energy even more valued. 
The optimal operation of a photovoltaic system depends on two types of variables; the first type is those that are imposed and depend on weather conditions, that is, irradiance and temperature. The second type of variables is those that can be modified to search for the desired performance of the system, given the weather conditions. This is the case that we are facing in this paper, that is, working at the maximum power point. In order to get it, it is mandatory to get an appropriate performance of the converter.

The search of control algorithms for improving converters performance in photovoltaic systems has a considerable significance for many researchers [2, 3]. Among different control algorithms, the sliding mode control is successful due to its many advantages [4-6], the most outstanding being its easy implementation, simplicity, robustness, and high performance in many fields such as robotics [7] or photovoltaic energy [8].

When a sliding mode controller is tuned by scientists or practitioners, it is desired to have a model of the photovoltaic module to control in order to carry out preliminary analytic or simulated tests instead of using the actual module. In the literature, there are a number of models of different complexities to explain the electrical behavior of photovoltaic modules. In order to clarify such variety, we can make a first division into theoretical and empirical models. Theoretical models use a characteristic equation [9] (see Section 2.1), among them being a number of models which use different degrees of freedom; that is, some of them are very complete but in other cases researchers determine/approximate them in several practical ways in order to get these models being useful.

The most complete model used in the literature is based on a double diode equivalent circuit which leads to a 7parameter model, that is, $a_{1}, a_{2}, R_{S}, R_{\mathrm{SH}}, I_{01}, I_{02}$, and $I_{\mathrm{PH}}$. Two-diode model has been used around the fifties [10, 11]. Later, Gow and Manning, using the same model, adjusted the parameters through Levenberg-Marquardt and NewtonRaphson algorithms [12]. This model is still being used in more recent literature $[13,14]$.

In [15], the approach used by Villalva et al. is to modify the value of $R_{S}$ and $R_{\mathrm{SH}}$ and adjust them by means of an iterative algorithm to fit the theoretical curve to experimental data in the MPP, implementing the complete model under SimulinkSimPowerSystem assisted by Simulink. De Soto et al. used this 5-parameter approach building three versions: from a basic model with two approximations of five magnitudes to a model where they are calculated [16]. They compared the results generated by this model with experimental data obtained from a facility by other researchers and studied the effect of changing $R_{\mathrm{S}}$ and $R_{\mathrm{SH}}$.

A number of researchers make some approximations of the characteristic parameters. The most usual of them is to assume that $R_{\mathrm{SH}}=\infty$, so $I_{\mathrm{SH}}=0 \mathrm{~A}$ and the third term of the characteristic equation is discarded leading to a 4-parameter model. In $[17,18]$, this simplification is carried out when the model of the exact same module is built following almost the same procedure. These works are quite similar to [19]. However, there are several differences: the first calculates the temperature coefficient $k_{0}$ used to calculate the short circuit current $I_{\mathrm{SC}}$, while the last one uses the value provided by the manufacturer; and the used numeric value of ideality factor of the diode is different between [17, 18] and [19]. A model where the ideality factor can be varied to fit it to different $\mathrm{PV}$ technologies is proposed in [20]. As a last 4-parameter model, Bayrak and Cebeci formulate a distinct model from the previous ones and develop the model of a microgrid facility and hybrid PV and fuel system [21].

Ramos-Hernanz et al. use polynomial interpolation and describe a model which allows obtaining only the $I V$ and $P V$ curves and provides further insight into the behavior of the photovoltaic module, but it is suited only for a range of temperatures and irradiances [22].

Another approach to the empirical methods is modeling the behavior of the photovoltaic elements by means of artificial neuronal networks [23]. In [24], an interesting review of different approaches is presented, while $[25,26]$ developed a practical model, but with very narrow amplitudes for irradiance and temperature. Lopez-Guede et al. are seeking to expand these limits [27], but in spite of expanding the range of magnitudes, they still obtain partial models with data captured during quite small time range (two months). Bonanno et al. use RFB neural networks to generate two models [28]. The former is to obtain $I_{\mathrm{PV}}$ from irradiance and voltage and uses 5,600 real samples. The second one is devoted to obtain $P_{\mathrm{PV}}$, again from irradiance and voltage using 4,600 real samples.

Researchers reported a relative MSE of $2 \%$ and $1 \%$, respectively, but the test has been done with training data, so in fact they have reported the training accuracy. In this paper, a new sliding mode controller (SMC) for maximum power point tracking in a photovoltaic module is introduced, and its performance is demonstrated in a real installation. Its main characteristic is that as reference generator it uses an artificial neural network which will seek for a reference current $I_{\mathrm{REF}}$ corresponding to the maximum power operating point $\left(I_{\mathrm{MPP}}\right)$. Gow and Manning have been developing works related to this paper; for example, in [12], they have used the facilities with a different photovoltaic module to design a control system that uses a voltage reference generator implemented through a polynomic equation.

In order to design the SMC controller, we have carried out several tasks related to the three main elements of the autonomous photovoltaic system (photovoltaic module, converter, and load):

(i) A model of the Mitsubishi Electric PV-TD185MF5 $185 \mathrm{~W}$ photovoltaic module has been developed based on neural networks, using actual measurements taken during 18 months, with an approximate average duration of ten minutes for each measure. A total of 62,912 samples $\left(I_{\mathrm{PV}}, V_{\mathrm{PV}}\right.$, temperature $T$, and irradiance $\left.G\right)$ have been obtained, covering a broad number of different weather situations.

(ii) These real data have been used to draw the characteristic curves of the module and calculate the MPP in each one of them. These points were learned by a second artificial neural network in order to obtain the reference current at which that the module operates 
at its optimum point, given the power supplied by the module and the temperature. That is, a neuronal reference current generator implementation has been obtained.

(iii) A SMC has been designed, so that, given a reference current, the photovoltaic module will work at its point of maximum power.

(iv) And finally, the joint behavior of all these components has been validated through simulated and real tests using the installation that is at the Faculty of Engineering Vitoria-Gasteiz (University of the Basque Country, Spain).

The document is structured as follows: in Section 2, we give a short background on some basic concepts used in this paper as photovoltaic generators, characteristic curves of photovoltaic modules, boost converters DC/DC, artificial neural networks, and sliding mode control. Section 3 describes how the model of a photovoltaic module has been obtained using artificial neural networks. In Section 4, we describe the sliding mode control, as well as the modeling process of the reference current generator, while the results obtained are discussed in Section 5. Finally, Section 6 gives our main conclusions.

\section{Background}

2.1. Photovoltaic Generator. A solar cell can be modeled as a PN semiconductor junction which when exposed to light converts light energy into electrical energy, generating a DC current which will mainly depend on the existing solar irradiance and temperature.

Electric generators are usually classified as current or voltage sources. A photovoltaic device shows a functional mixed behavior, which is a source of current or voltage depending on the operating point in which the device is working.

Most manufacturers provide few experimental data on the performance of solar cells working at ideal operating conditions. These data are typically provided in Standard Test Conditions (STC) $\left(1,000 \mathrm{~W} / \mathrm{m}^{2}, 25^{\circ}( \pm 2)^{\circ} \mathrm{C}, \mathrm{AM} 1.5\right.$ according to EN 6090-4). There are manufacturers that also provide these data for other conditions $\left(800 \mathrm{~W} / \mathrm{m}^{2}\right.$, Nominal Operating Cell Temperature (NOCT), AM 1.5). Usually the provided data are short circuit current $\left(I_{\mathrm{SC}}\right)$, open circuit voltage $\left(V_{\mathrm{OC}}\right)$, current at the maximum power point $\left(I_{\mathrm{MPP}}\right)$, voltage at the maximum power point $\left(V_{\mathrm{MPP}}\right)$, temperature coefficient of open circuit voltage $V_{\mathrm{OC}}\left(K_{V}\right)[\% / \mathrm{K}]$, and temperature coefficient of short circuit current $I_{\mathrm{SC}}\left(K_{I}\right)$ $[\% / \mathrm{K}]$.

The basic model of a photovoltaic generator is a photovoltaic cell. The cell can be modeled as a diode, usually made of silicon and designed to maximize the absorption of photons and to minimize the reflection, converting a part of the received solar energy to electric energy. The ideal cell model is presented in the dotted area of Figure 1.

However, there are some recombination phenomena in the material, specifically in the depletion layer of the

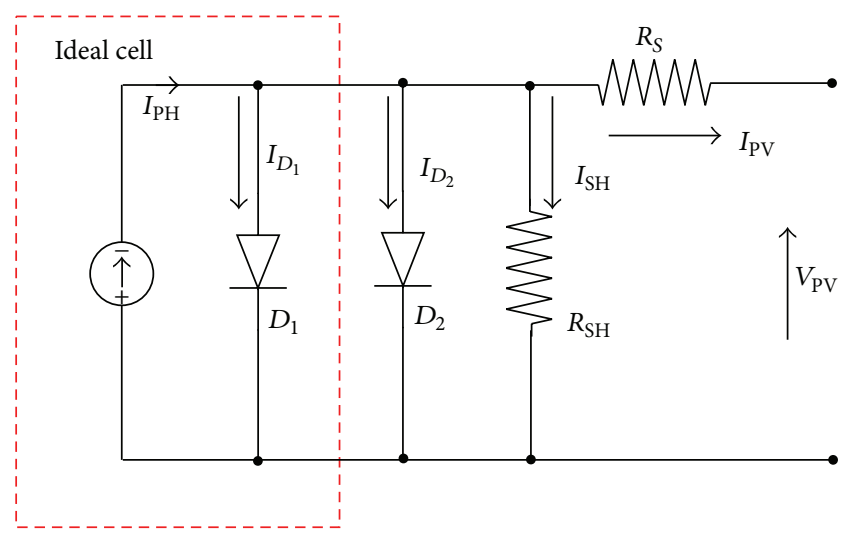

Figure 1: Two-diode model of a photovoltaic cell.

semiconductor which can be modeled through a second diode, leading to a two-diode model. The typical two-diode equivalent circuit of a photovoltaic cell is shown in Figure 1.

Analyzing the schema of Figure 1, we define the following equations:

$$
\begin{gathered}
I=I_{\mathrm{PV}}=I_{\mathrm{PH}}-I_{D_{1}}-I_{D_{2}}-I_{\mathrm{SH}} \\
I=\left[\begin{array}{c}
\overbrace{\mathrm{PH}}^{I_{\mathrm{PH}}}-\overbrace{I_{01} \cdot\left(e^{q\left(V+I R_{\mathrm{S}}\right) / a k T}-1\right)}^{I_{\mathrm{D} 1}} \\
-\overbrace{I_{02} \cdot\left(e^{q\left(V+I R_{\mathrm{S}}\right) / a k T}-1\right)}^{I_{\mathrm{D}_{2}}} \\
-\frac{I_{I_{\mathrm{H}}}^{\left(V+I R_{S}\right)}}{R_{\mathrm{SH}}}
\end{array},\right.
\end{gathered}
$$

where $I_{01}$ is a saturation current of diode $1(\mathrm{~A}), I_{02}$ is a saturation current of diode $2(\mathrm{~A}), V$ is a cell voltage $(\mathrm{V}), q$ is the charge of an electron $\left(1.6 \times 10^{-19} \mathrm{C}\right), a$ is the diode ideality constant, $k$ is Boltzmann's constant $1.38 \times 10^{-23}(\mathrm{~J} / \mathrm{K})$, and $T$ is the cell temperature.

Many researchers use some simplifications obtaining equations that define the model of a single diode [17-20] due to its simplicity and reliability.

Analyzing the schema of Figure 2, we define the following equations:

$$
\begin{aligned}
& I=I_{\mathrm{PV}}=I_{\mathrm{PH}}-I_{D}-I_{\mathrm{SH}}, \\
& I=\overbrace{\mathrm{I}}^{I_{\mathrm{PH}}}-\overbrace{I_{0} \cdot\left(e^{q\left(V+I R_{S}\right) / a k T}-1\right)}^{I_{D}}-\frac{\overbrace{\left(V+I R_{S}\right)}^{I_{\mathrm{SH}}}}{R_{\mathrm{SH}}} .
\end{aligned}
$$

There are a number of data which cannot be found in data sheets as series resistance $\left(R_{\mathrm{S}}\right)$, shunt resistance $\left(R_{\mathrm{SH}}\right)$, diode ideality constant $(a)$, and saturation current of the diode $\left(I_{0}\right)$.

Both (2) and (3) are similar, but (3) has been expanded representing the output current generated by the module $\left(I_{\mathrm{PV}}\right)$ which depends on the voltage of the photovoltaic module $\left(V_{\mathrm{PV}}\right)$ and on solar radiation and temperature on the photovoltaic module. 


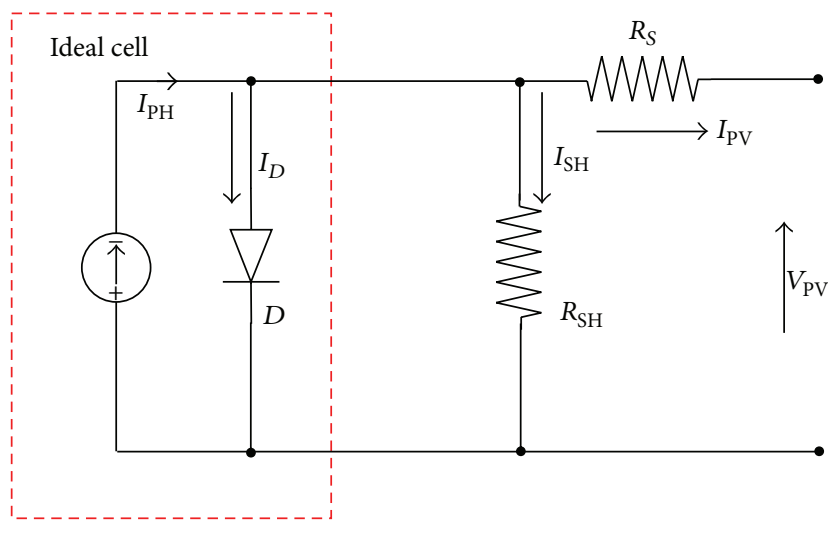

FIGURE 2: One-diode model of a photovoltaic cell.

We define the current produced between electrodes of a photocell as the photogenerated current or photocurrent according to

$$
I_{\mathrm{PH}}=\left(\frac{G}{G_{\mathrm{REF}}}\right)\left(I_{\mathrm{SC} \_\mathrm{REF}}+K_{I_{\mathrm{sc}}}\left(T-T_{\mathrm{REF}}\right)\right) \text {, }
$$

where $G$ is working irradiance $\left(\mathrm{W} / \mathrm{m}^{2}\right), G_{\mathrm{REF}}$ is the reference irradiance (usually $1,000 \mathrm{~W} / \mathrm{m}^{2}$ ), $I_{\text {SC_REF }}$ is the short circuit current of reference (A), $K_{I_{s c}}$ is the temperature coefficient of short circuit current $\left(\% /{ }^{\circ} \mathrm{C}\right), T$ is the cell temperature $\left({ }^{\circ} \mathrm{C}\right)$, and $T_{\mathrm{REF}}$ is the reference temperature (usually $25^{\circ} \mathrm{C}$ ).

Moreover, the reverse saturation current of the diode $\left(I_{0}\right)$ can be defined as shown:

$$
\begin{aligned}
I_{0 \_ \text {REF }} & =\frac{I_{\text {SC_REF }}}{e^{\left(q V_{\text {OC_REF }} / a k T_{\text {REF }}\right)-1}} \\
I_{0} & =I_{0 \_ \text {REF }}\left(\frac{T}{T_{\text {REF }}}\right)^{3} e^{\left[\left(q E_{g} / a k\right)\left((1 / T)-\left(1 / T_{\mathrm{REF}}\right)\right)\right]},
\end{aligned}
$$

where $V_{\text {OC_REF }}$ is the open circuit reference voltage and $E_{g}$ is the band gap energy (for silicon it has a value of $1.11 \mathrm{eV}$ at $\left.300^{\circ} \mathrm{K}\right)$.

In order to apply these concepts to the development of a solar cell model, we have chosen the PV-Mitsubishi TD1185MF5 PV module for its modeling. This module has 50 polycrystalline cells connected in series. Its main characteristics are specified in Table 1.

2.2. Characteristic Curves. One of the best tools to describe the operation of a photovoltaic module is the current-voltage $(I-V)$ relationship, that is, the $I-V, P-V$, and $P-I$ characteristic curves. The $I V$ curve of an ideal solar cell is superimposing the $I-V$ curve of the diode and the photogenerated current. These curves result from mathematical expressions that describe the behavior of the photovoltaic cells which constitute the module.

Conceptually, the $I-V$ curve represents the current and voltage combinations in which the cell might work if the irradiance and cell temperature could be maintained constant. The same applies to $P-I$ curves (power-current) and $P-V$ (power-voltage).
TABle 1: Key specifications of the Mitsubishi PV module.

\begin{tabular}{lc}
\hline Manufacturer & Mitsubishi \\
\hline Model & PV-TD185-MF5 \\
Cell type & Polycrystalline \\
Maximum power $[\mathrm{W}]$ & 185 \\
Open circuit voltage $V_{\mathrm{OC}}[\mathrm{V}]$ & 30.60 \\
Short circuit current $I_{\mathrm{SC}}[\mathrm{A}]$ & 8.13 \\
Voltage at $P_{\mathrm{MPP}}[\mathrm{V}]$ & 24.40 \\
Current at $P_{\mathrm{MPP}}[\mathrm{A}]$ & 7.58 \\
Temperature coefficient of $V_{\mathrm{OC}}\left[\% /{ }^{\circ} \mathrm{C}\right]$ & -0.346 \\
Temperature coefficient of $I_{\mathrm{SC}}\left[\% /{ }^{\circ} \mathrm{C}\right]$ & 0.057 \\
Nominal operating cell temperature $(\mathrm{NOCT})\left[{ }^{\circ} \mathrm{C}\right]$ & 47.5 \\
\hline
\end{tabular}

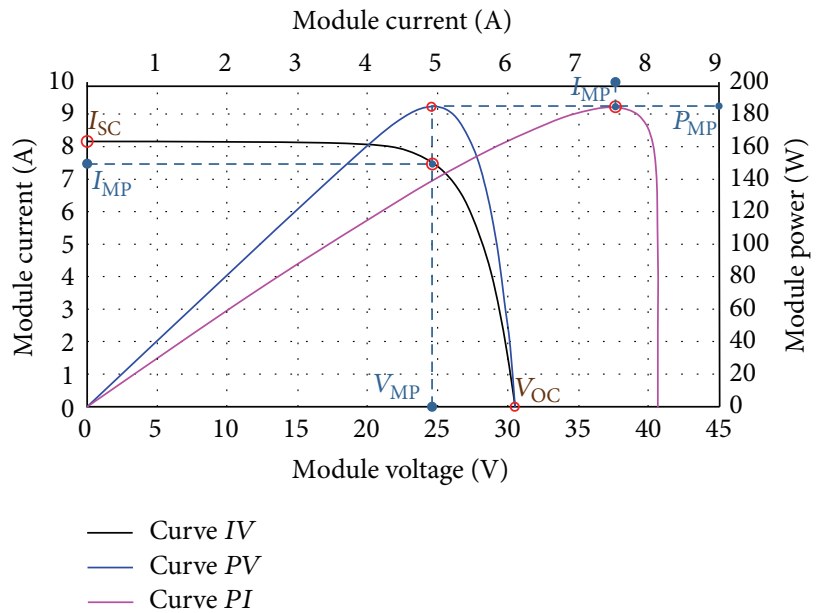

FIGURE 3: Characteristic curves of a photovoltaic module.

In order to evaluate the performance of solar cells and the photovoltaic systems design, we will rely on the electrical characteristics, that is, in the relations of voltage-current of the cells under different levels of radiation and temperatures. This requires understanding how solar radiation, the cell temperature, and electrical loads affect the behavior of the characteristic curves. The particular point of current and voltage of the curve at which the photovoltaic device works is determined by the load to which it is connected. If we have a high knowledge of these curves we can make a correct photovoltaic system design and an appropriate evaluation.

Figure 3 shows the characteristic curves $I-V$ (black), $P-V$ (blue), and $P-I$ (magenta) of a module operating at a given temperature and irradiation. If these factors are changed, the obtained curves will be different. The inferior abscissa axis represents the working voltage $(\mathrm{V})$ of the module and, in the upper one, the current (A). The current (A) is shown in the left ordinate axis, while the obtained power (W) is in the right one.

2.3. Boost DC/DC Converter. A DC converter must provide at its output a regulated DC voltage of a desired value. It must be done in the most efficient way and with as fewer losses as possible. 


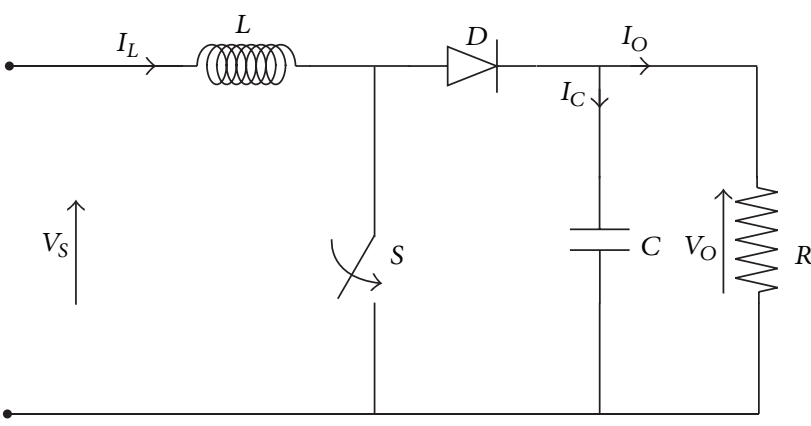

(a)

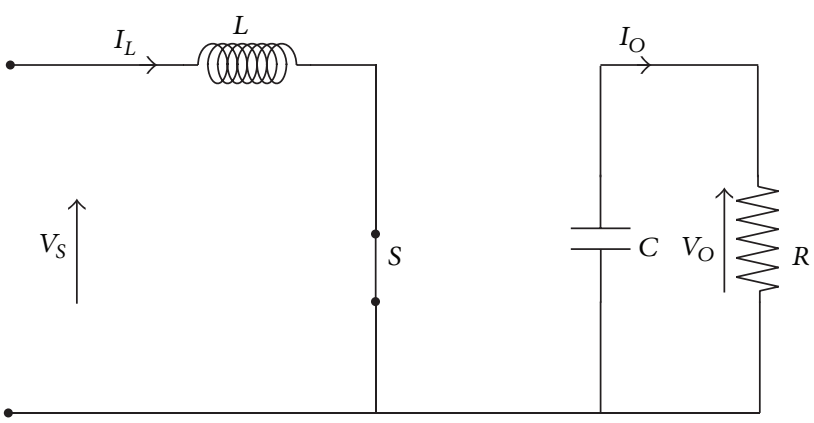

(b)

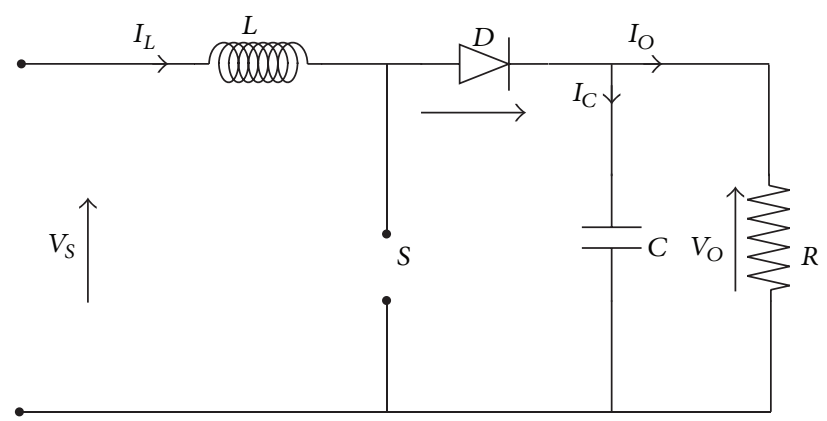

(c)

FIGURE 4: BOOST converter.

The most commonly used method to control the output voltage is the pulse width modulation (PWM), which consists in using a constant switching time $(T)$. This time is the sum of driving time $\left(T_{\mathrm{ON}}\right)$ plus the blocking time $\left(T_{\mathrm{OFF}}\right)$, and varying the driving time $\left(T_{\mathrm{ON}}\right)$, it is possible to control the output average voltage.

The power given to the load is a function of the duty cycle $(\delta)$, which is defined as the relation between the time in which the converter is driving $\left(T_{\mathrm{ON}}\right)$ and the switching time $(T=$ $\left.T_{\mathrm{ON}}+T_{\mathrm{OFF}}\right)$, that is, $\delta=T_{\mathrm{ON}} / T$.

In photovoltaic systems, the DC/DC converter is placed between the PV generator and load, being responsible for adapting the energy produced by the generator following a defined control strategy, which usually tries that the system works at the maximum power point to increase the efficiency of the installation.

A concrete type of converter that we have used in our installation due to its characteristics is the boost converter. It provides an average output voltage exceeding the input value. We can see the converter topology in Figure 4(a).

These converters are nonlinear circuits, so in order to study them as linear circuits it is usual to decompose them into two subcircuits. Its linear operation mode depends on the state of the switch $(S)$ :

(i) When the switch $(S)$ is closed (see Figure 4(b)) during $T_{\mathrm{ON}}$, the diode $(D)$ is reversing biased, isolating the input and the output stages. The primary source voltage $\left(V_{S}\right)$ is applied to the coil $(L)$, which causes the $\left(I_{L}\right)$ current to increase and thus the energy is stored in the coil $(L)$. The load $\left(R_{O}\right)$ is fed only by the capacitor $(C)$.

(ii) When the switch $(S)$ is open (see Figure 4(c)) during $T_{\text {OFF }}$, the diode is polarized. The voltage of the coil $(L)$ is then added to the voltage of the primary source $\left(V_{S}\right)$, providing at the output a larger voltage $\left(V_{O}\right)$, larger than that of the primary source $\left(V_{S}\right)$ and with the same polarity. In this way, the load $\left(R_{O}\right)$ is fed by the coil $(L)$ and the primary source $\left(V_{S}\right)$.

In the case of a boost converter in continuous driving operating mode, the relations between the input $\left(V_{S}, I_{S}\right.$, and $\left.R_{\mathrm{PV}}\right)$ and output $\left(V_{\mathrm{O}}, I_{\mathrm{O}}\right.$, and $\left.R_{\mathrm{O}}\right)$ variables are given by

$$
\begin{aligned}
& V_{\mathrm{O}}=\frac{V_{S}}{(1-\delta)}, \\
& I_{O}=I_{S}(1-\delta), \\
& R_{O}=\frac{R_{\mathrm{PV}}}{(1-\delta)^{2}} .
\end{aligned}
$$

Analyzing (6), we can notice that as $\delta \in(0,1]$, the converter increases the voltage and reduces the current.

The dynamic model of a circuit of a boost converter is defined by

$$
\begin{aligned}
\frac{d I_{L}}{d t} & =\frac{V_{S}}{L}+\frac{1}{L}(u-1) V_{O} \\
\frac{d V_{O}}{d t} & =\frac{1}{C}\left(I_{L}-I_{O}\right)-\frac{1}{C} u I_{L},
\end{aligned}
$$


where $u \in\{0,1\}$ represents the operation mode of the circuit when $u=1$ (Figure 4(b)) and when $u=0$ (Figure 4(c)). Finally, we can rewrite (7) as

$$
\begin{aligned}
\dot{x} & =f(x)+g(x) u, \\
x & =\left[\begin{array}{c}
I_{L} \\
V_{O}
\end{array}\right] ; \\
f(x) & =\left[\begin{array}{c}
\frac{V_{S}}{L} \\
\frac{1}{C}\left(I_{L}-\frac{V_{O}}{R}\right)
\end{array}\right] ; \\
g(x) & =\left[\begin{array}{c}
-\frac{V_{O}}{L} \\
-\frac{I_{L}}{C}
\end{array}\right] .
\end{aligned}
$$

2.4. Artificial Neural Networks. Artificial neural networks (ANNs) are based on the operation mode of biological neural networks, although they have different functions and structures. ANNs try to mimic the human brain which is a very complex, nonlinear, and parallel system. In other words, it can perform many simultaneous operations unlike traditional computers, which only can perform one sequential operation at the same time.

The basic component of calculation is usually called neuron, node, or unit. It receives one or more inputs $\left(x_{i}\right)$ from other units or from an external data source. Each input has an associated weight $\left(w_{i j}\right)$, which is modified during the training process. The output $\left(y_{i}\right)$ of each unit is a function of the sum of the weighted inputs, as shown in Figure 5:

$$
y_{i}=f\left(\sum_{j} w_{i} y_{j}\right) .
$$

The main characteristics of the ANNs are the following:

(i) Adaptive Learning. It is the process by which ANN can change their weights in response to input information. They learn to carry out tasks by means of training with examples or by an initial experience. They differentiate patterns by examples and can change their behavior depending on the environment, having a natural suitability to acquire knowledge through experience.

(ii) Self-Organization. They use their learning ability to organize the information that they receive during the learning and/or operation. They can change their internal structure in order to perform a specific task.

(iii) Nonlinear Processing. It allows them to process information from nonlinear phenomena. It increases network capacity to approximate functions and sorting patterns and increase their immunity to noise.

(iv) Parallel Processing. Usually, a large number of processing nodes are used, with a high level of interconnectivity.

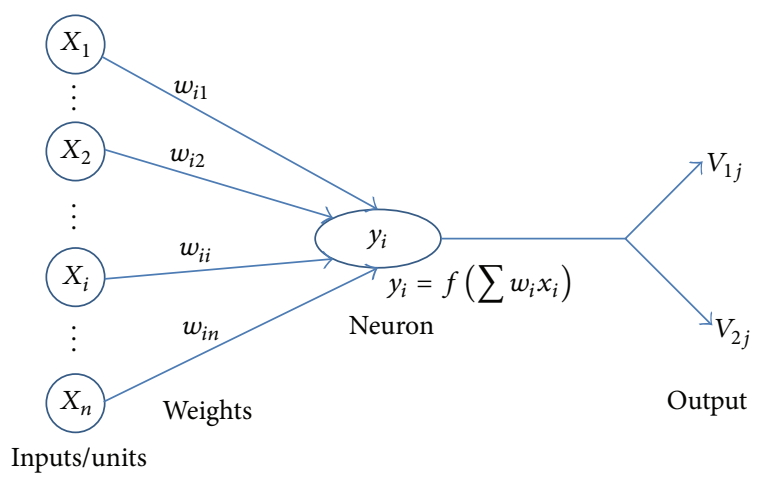

FIGURE 5: Generic artificial neural network structure.

(v) High Level of Fault Tolerance. If a fault occurs even in a small number of neurons, although the system might be influenced, it does not suffer a sudden drop; that is, they can suffer considerable damage and continue to have an acceptable behavior. They have this capability because the information is stored in a distributed way.

(vi) Real-Time Operation. They can face large processes quite quickly because ANNs are perfectly suited due to their parallel implementation.

(vii) Easy Insertion into Existing Technologies. Thanks to the ease and speed that they can be trained and validated, ANNs can be transferred easily to an implementation in specific applications within existing or legacy systems.

2.5. Sliding Mode Control. The sliding mode control (SMC) is defined as using a control signal, switching at high frequency in order to carry the system state to a scalar field. The structure of the controller varies so that a representative point of the system follows a defined trajectory in the state space. It is based on the fact that it is easier to control first-order systems than those of order $n$. For this purpose, systems of order $n$ are replaced by first-order equivalent systems.

The advantages of SMC are great accuracy, good stability, simplicity, and ruggedness, especially when the dynamics of the system in closed loop slides by the sliding surface, because it remains insensitive to variations in the model parameters and to external perturbations.

2.5.1. Sliding Surface. If in a system there is a sliding mode, the trajectories that intersect the sliding region remain on $S(x)$ except when they reach the end of the sliding surface. If the trajectory goes on the surface, it is said that the system is in sliding mode, as in Figure 6.

In order to analyze this technique, we will consider a nonlinear dynamical system defined by the following equations:

$$
\dot{x}=f(x)+g(x) u, \quad x \in \mathfrak{R}^{n}, u \in \Re,
$$

where $x$ is the output of interest, $u$ is the discontinuous control input which can take the values 0 and 1 (their discontinuity points correspond with the shape changes of 


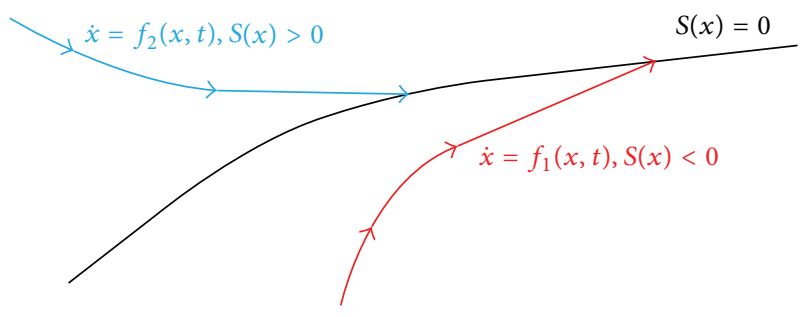

FIGURE 6: Sliding surface.

the converter), $X=[x, \dot{x}, \ldots]^{T}$ is the state vector, $f(X)$ is the function that describes the system, and $g(X)$ is the control gain.

The variable sliding surface in time domain is defined in the state space $\Re^{n}$ by the equation $S(X)=0$ in which

$$
S(X)=\left(\frac{d}{d t}+\lambda\right)^{(n-1)} e(X),
$$

where $\lambda$ is a strictly positive constant corresponding to the bandwidth of the control system, $n$ is the number of times that must be derived to the surface to gain control, and $e(X)=$ $\left(x^{*}-x\right)$, where $x$ is the control variable and $x^{*}$ its reference value.

The purpose of the control is to keep the surface to zero. This is a linear differential equation whose unique solution is $e(X)=0$ for a proper choice of $\lambda$ regarding the convergence condition.

We define the following control signal:

$$
u(t)=\left\{\begin{array}{l}
u=0 \Longleftrightarrow S(X)<0 \Longleftrightarrow \frac{d S}{d t}>0, \\
u=1 \Longleftrightarrow S(X)>0 \Longleftrightarrow \frac{d S}{d t} \leq 0 .
\end{array}\right.
$$

We say that the converter is controlled in sliding mode when the law described by (12) is enforced and there is a region where there is a sliding mode. Then $S$ is a sliding region.

If the dynamics of the system are out of the sliding region and they are above it, the control will switch to the value $u=1$ in order to bring the system dynamics into the sliding region $S(X)$. Otherwise, if they are below the sliding region, the control system changes to the value $u=0$ to bring again the system dynamics to the sliding surface.

The execution of the control law to get the system to slide across the surface means that the switching frequency is infinite, which is physically impossible. Therefore, we will use a modified control law expressed in

$$
u(t)=\left\{\begin{array}{l}
u=0 \Longleftrightarrow S(X) \leq-\Delta \\
u=1 \Longleftrightarrow S(X) \geq \Delta,
\end{array}\right.
$$

where $\Delta$ is a positive constant. When $\Delta$ tends to zero, it is said that the system tends to ideal sliding dynamics. The switching frequency is not kept constant, but changes could be finite when it does on the surface.
2.5.2. Invariance Conditions. The sliding surface is characterized by the following conditions of invariance or ideal sliding dynamics of (14), and the state trajectories evolve on it:

$$
\begin{aligned}
S(X) & =0, \\
\frac{d S(X)}{d t} & =0 .
\end{aligned}
$$

These conditions guarantee that the trajectory of the system state is addressed to the sliding surface $(S=0)$ and slides on it.

System stability can be analyzed using the method of Lyapunov stability. The Lyapunov function is a scalar positive function. The desired function is one that ensures monitoring of the variable to control the reference value. We define the positive function of the form $V$ in

$$
V=\frac{1}{2} S^{2}>0
$$

If the function is derived, (16) is obtained:

$$
\dot{V}=S \cdot \frac{d S}{d t}=S \cdot \dot{S}
$$

The function decreases if the derivative is negative.

A system meets the slip condition when the scalar $S(X)$ is zero and it met the condition of

$$
\frac{d}{d t} S^{2} \leq-\eta|S|
$$

where $\eta$ is a strictly positive constant indicating the force of attraction of the path to the sliding surface. Once the system is on the surface, the system trajectories remain on it.

\section{Module Developed}

This section will describe the steps taken for modeling the Mitsubishi PV-TD185-MF5 module. It is located on the roof of the Faculty of Engineering of Vitoria-Gasteiz (University of the Basque Country, Spain). The model is obtained from experimental data (32,916 samples), taken during 18 months. The measurements were made randomly with an approximate average duration of ten minutes, during which four magnitudes were measured (temperature, irradiance, current, and voltage) varying the load resistance.

3.1. Data Acquisition. Figure 7 shows a schematic diagram with all the devices involved to capture the four relevant magnitudes, that is, $V_{\mathrm{PH}}, I_{\mathrm{PH}}$, temperature $T$, and irradiance $G$ in the surroundings of the photovoltaic module. The voltmeter is placed in parallel with the module to obtain $V_{\mathrm{PH}}$, while the ampere meter is placed in series to obtain $I_{\mathrm{PH}}$.

Besides, there is a variable resistance to act as a variable load and obtain different pairs of voltage and current with the same irradiance and temperature. The variable resistance value is controlled according to our convenience, but the temperature and the irradiance depend on the climatological conditions. 


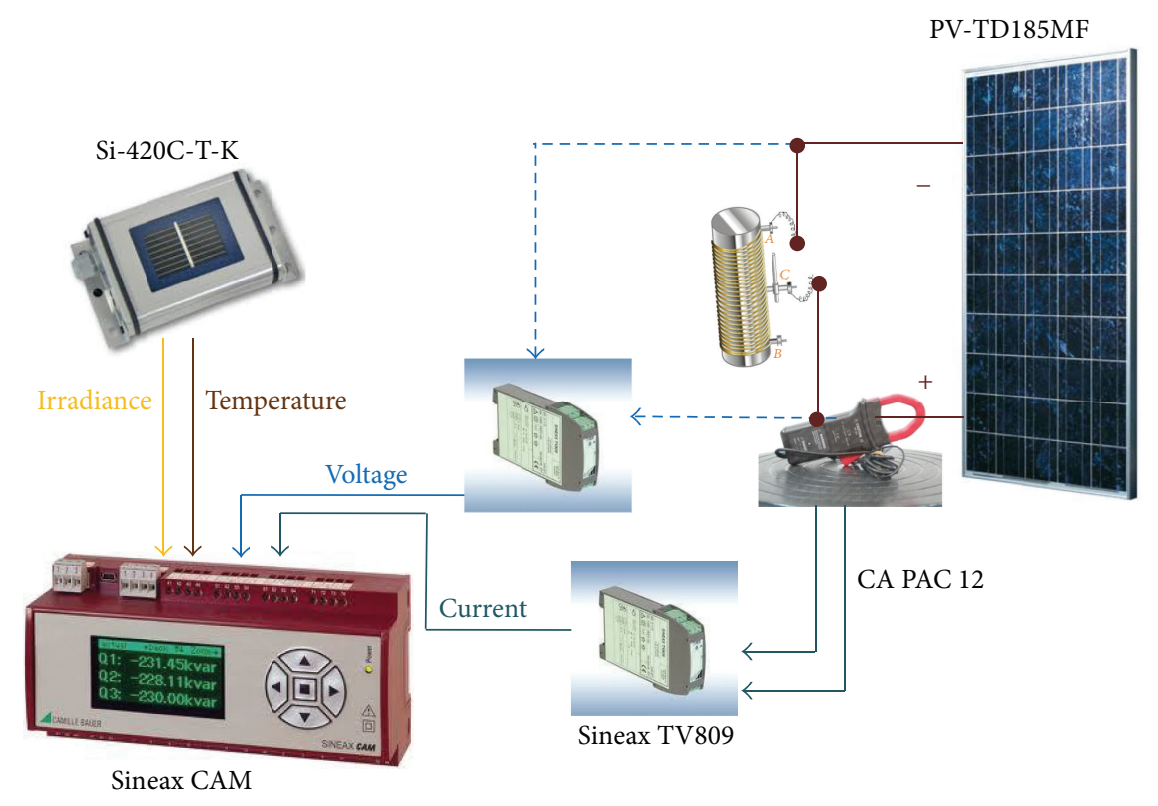

FIgURE 7: Scheme of measurement elements for data logging.

The involved measurement elements for data logging are the following:

(i) Irradiance and Temperature Sensor (Si-420TC-T-K). This sensor provides the irradiance $\left(\mathrm{W} / \mathrm{m}^{2}\right)$ and the temperature $\left({ }^{\circ} \mathrm{C}\right.$ ) of its cell (placed next to the photovoltaic module) along the duration of the data acquisition process, which usually is not long. Once the sensor acquires a stable working temperature, both irradiance and temperature values have usually a very small variation; therefore, they are assumed as constants by manufacturers when providing the $I$ $V$ and $P-V$ characteristic curves of their photovoltaic modules. The sensor provides its output expressed as current. With regard to the accuracy of the device, it is $\pm 5 \%$ when it measures irradiance and $\pm 1.5^{\circ} \mathrm{C}$ when it measures temperature.

(ii) Clamp Current Chauvin Arnoux PAC 12. The current clamp is used to measure the direct current provided by the photovoltaic module, providing at its output a voltage proportional to the measured current. This clamp has two working scales: one with a narrow input range ( 0.4 to $60 \mathrm{~A}$ DC) but more accurate readings (precision $\pm 1.5 \%$ ) and a second one with a broader input range ( 0.5 to $600 \mathrm{~A} \mathrm{DC})$ but with less accurate readings (precision $\pm 2 \%$ ). Since the expected value of $I_{\mathrm{PV}}$ is less than $10 \mathrm{~A}$, we have chosen the first working mode, which leads to measurements with a maximum error of $\pm 150 \mathrm{~mA}$.

(iii) Programmable Amplifier with Insulation SINEAX TV809. The functions of this device are to isolate electrically the input/output signals and amplify and/or convert the signal level or type (current to voltage or vice versa) of the input DC signals. In the experiments described in this paper, we have used two independent devices. Since the value of both $V_{\mathrm{PV}}$ and the output of the current clamps $I_{\mathrm{PV}}$ are expressed in volts, and the used data logger only can read currents at its input, it is mandatory to use two independent devices to transform these magnitudes into current values. The configuration of the transformations to carry out is done through the TV800plus (V1.11) software, and the main function of both amplifiers is to convert the voltage and current signals of the photovoltaic module into a 4-20 mA current signal proportional to the input. The accuracy of this device is $\pm 0.2 \%$ of the maximum value of the input. In the case of $V_{\mathrm{PV}}$, the maximum value is set to $50 \mathrm{~V}$, leading to maximum error of $\pm 0.1 \mathrm{~V}$, while the maximum value of $I_{\mathrm{PV}}$ is set to $10 \mathrm{~A}$, leading to maximum error of $\pm 20 \mathrm{~mA}$.

(iv) SINEAX CAM Data Logger. This device is devoted to collect and register the four physical magnitudes that later will be used to elaborate the datasets to obtain different approximations as realistic as possible, that is, irradiance, temperature, $V_{\mathrm{PH}}$, and $I_{\mathrm{PH}}$. It is designed for long-term measurements in industrial installations, and it allows continuous measurement and recording of data. In our case, the logging frequency was set to $0.5 \mathrm{~Hz}$. The data logger is supplied with the CB-Manager software, which integrates several useful functions to configure the $I / O$ interface according to specific requirements and to display the measured values. The accuracy of this device is $\pm 0.1 \%$ of the maximum value of the input configuration (full scale) which is set to $20 \mathrm{~mA}$, so the measurement error is negligible. 
The data measured and recorded using the CB-Manager are saved in plain ASCII files. After some minor modifications as changing decimal sign (. by ,) and separator (, by ;) and eliminating unnecessary data, these files are imported into a Microsoft Excel file in order to obtain graphics which allow detecting outliers or corrupted data, so that a single file with 62,916 samples of measured data (current $I_{\mathrm{PV}}$, voltage $V_{\mathrm{PV}}$, irradiance $G$, and temperature $T$ ) is obtained.

3.2. Obtaining Photovoltaic Module Model. We import these data into the MathWorks Matlab environment and generate four vectors, one for each measured magnitude. Since we will use an artificial neural network to generate the model, with these vectors we form the network input and output, in such a way that the generated neural network will have three-dimensional input patterns $\left(T, G\right.$, and $\left.V_{\mathrm{PV}}\right)$ and a single output value $I_{\mathrm{PV}}$ associated with each combination of inputs. Once we have defined the model to learn, we must fix the structure of the ANN and train and validate the learned model.

During the structure design phase, we heuristically chose a one-layer feed-forward artificial neural network composed of three inputs, one output, and 15 nodes in the hidden layer. Once the network architecture was designed, we proceed to train it to learn the desired behavior defined through the input and output correspondences. In this phase, the ANN calculates its predictions and compares them with the actual values of the variable that had tried to predict them, so that the network learns that there were erroneous predictions and modifies the synaptic weights in order to reduce that error. This process is driven by a training algorithm, which presents sequentially the training data at the input layer of the ANN. In this case, the Levenberg-Marquardt algorithm has been used. We call "epoch" to a complete presentation of all training data during the learning process. Learning occurs epoch to epoch until the weights and thresholds are stabilized and the error criterion on the complete training set converges to a minimum value following a metric, in our case, the Mean Square Error (MSE).

After training phase, it is expected that the ANN shows a behavior similar to the actual photovoltaic module, even when new inputs are presented at its input layer.

Of the total number of 62,916 samples of experimental data obtained, we use 44,042 samples pairs for training (70\%), 9,437 for validation (15\%), and the remaining 9,437 for test (15\%). The network was trained with backpropagation Levenberg-Marquardt algorithm during 1000 epochs, obtaining a network with a Mean Squared Error (MSE) of $6.1553 \times$ $10^{-2} \mathrm{~A}$ and with a training correlation coefficient $R=0.99075$, as shown in Figure 8.

3.3. Validation of the Model. In Figure 9, there are the characteristic $I-V$ curves of three different days in different weather conditions: the experimental values (blue) and the predicted values by the ANN-based model (red). We can see that the model provides a prediction very similar to the actual values obtained through experimental measurements.

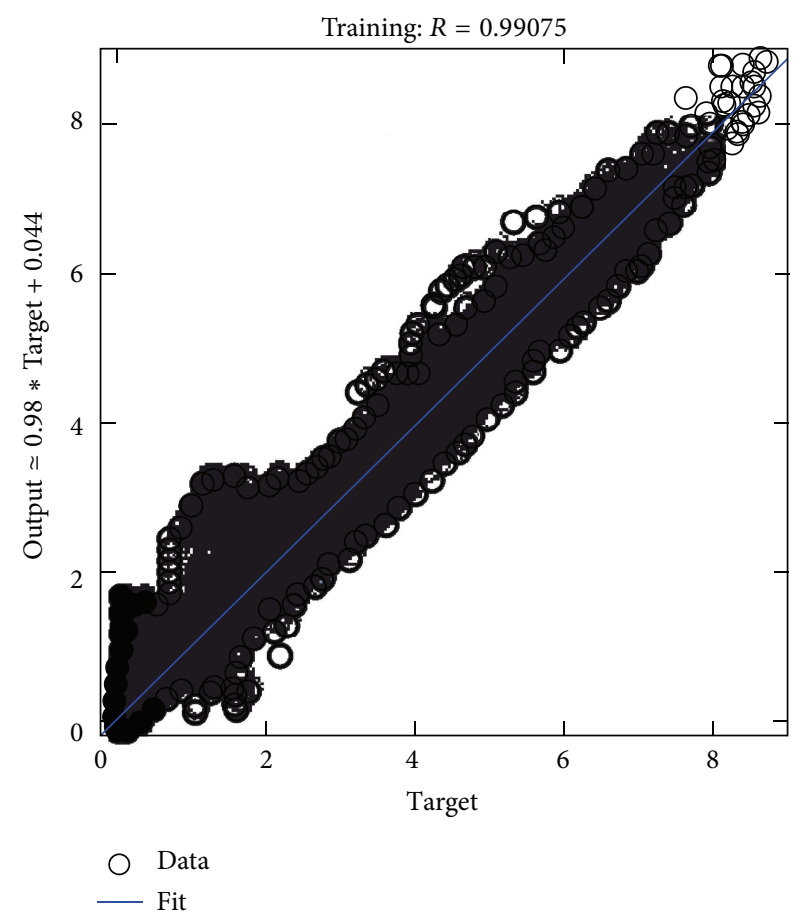

FIgURE 8: Training correlation coefficient.

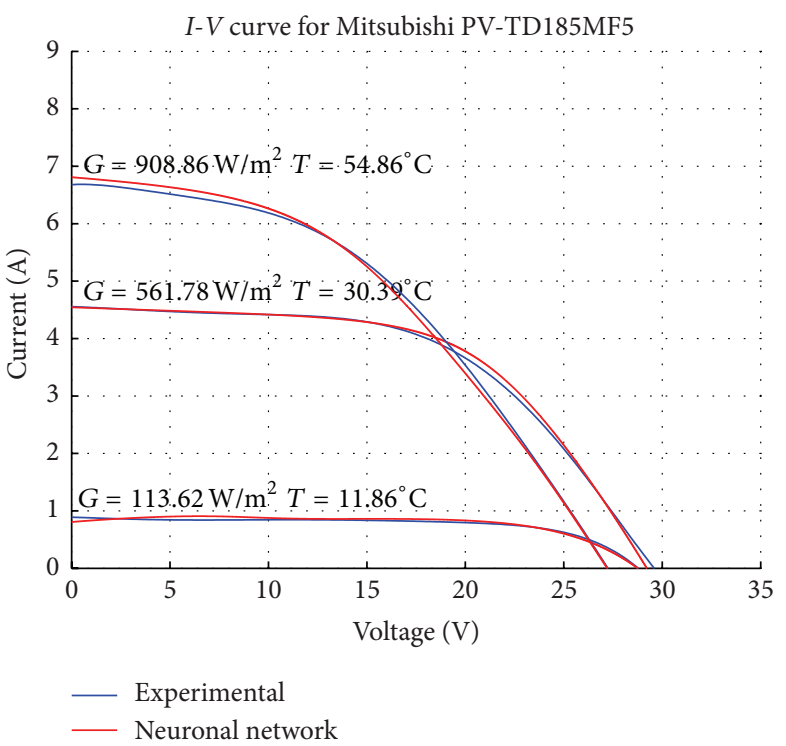

FIGURE 9: Model validation.

Moreover, using a test dataset of 9,437 samples a test correlation coefficient $R=0.99069$ has been achieved as shown in Figure 10.

With these results, we can state that the model is accurate enough to be used in those studies where the Mitsubishi PVTD185MF module is implied. 


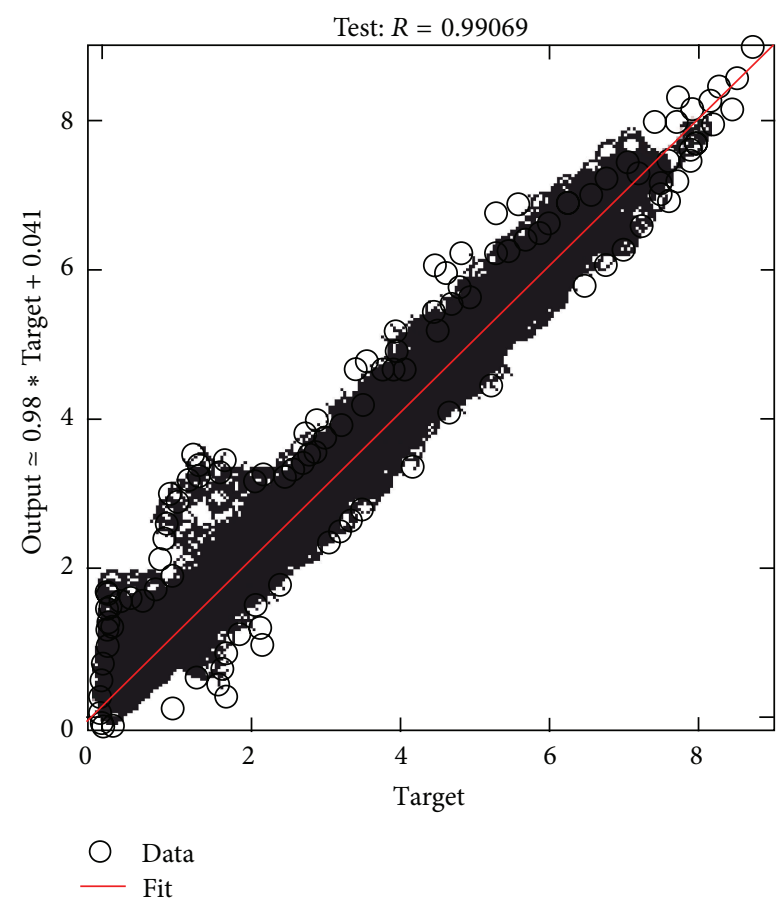

Figure 10: Test correlation coefficient.

\section{Sliding Mode Control}

4.1. Reference Current Generator. Boost converter function is to take the output of the photovoltaic module and transform it to obtain the maximum power. The behavior of the converter depends on the sliding control which obtains the reference $(\delta)$ necessary for the IGBT inverter to find the maximum power point. In turn, the sliding mode controller needs a reference current $\left(I^{*}\right)$ to compare with the current of the photovoltaic generator and to obtain such pulse $(\delta)$. The reference current generator is which is going to give us this reference current $I^{*}$.

In order to obtain the reference current generator $\left(I_{\mathrm{REF}}\right)$, we rely on the $P-I$ characteristic curve. As can be seen in Figure 11, maximum power points at different irradiance conditions form a straight blue line, instead of the quadratic equation that results if $P-V$ characteristic curve is used.

Knowing this line, for any power value, it is straight to know which current value, at the maximum power point, that should be used as reference current. Since the power generated by the module also depends on the temperature, it is necessary to obtain these straight lines at different temperature values.

4.2. Experimental Current Reference Generator Design. In order to design the reference current generator, we will use the same experimental data used to obtain the model of the photovoltaic module in Section 3.

In this case, the 62,192 samples will be divided into groups of temperature of $5^{\circ} \mathrm{C}$, going from $5^{\circ} \mathrm{C}$ to $50^{\circ} \mathrm{C}$. Each one of these groups is divided again into irradiance groups with values from 100 to $1,000 \mathrm{~W} / \mathrm{m}^{2}$ and step $100 \mathrm{~W} / \mathrm{m}^{2}$. With

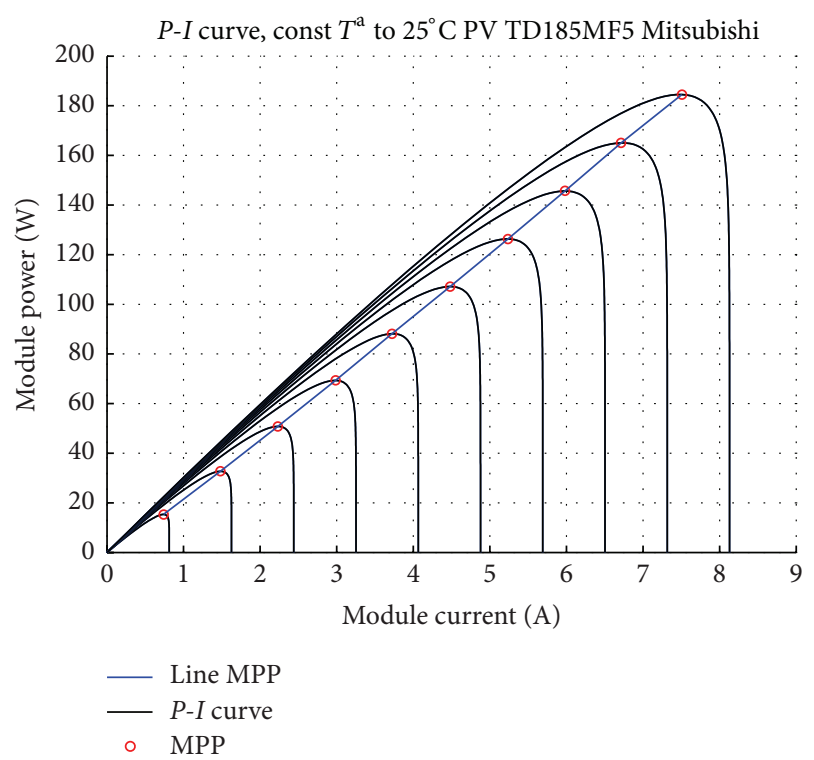

Figure 11: $P-I$ characteristic curves of the module at different irradiance conditions.

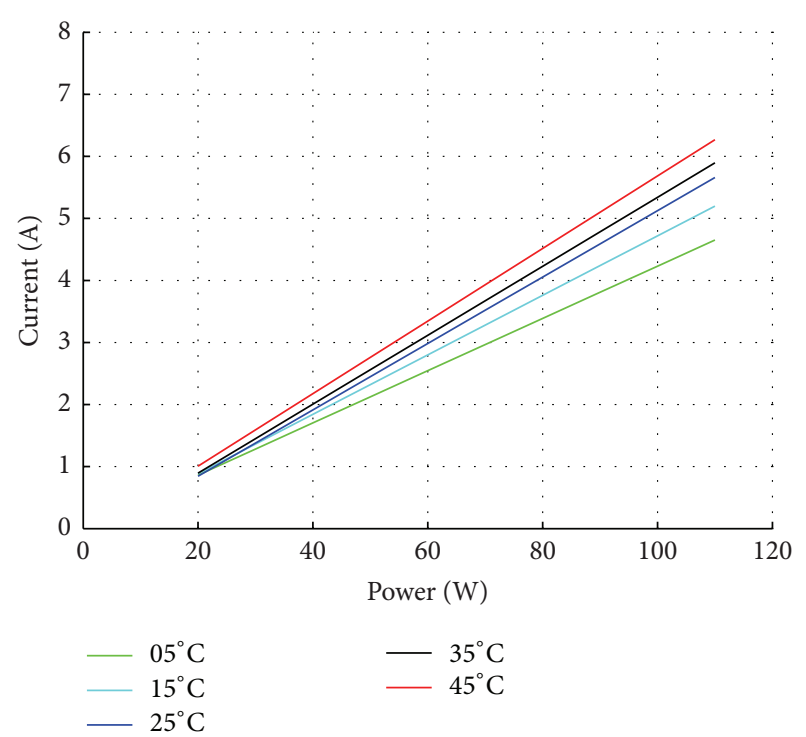

Figure 12: Lines of MPP for different temperatures $\left({ }^{\circ} \mathrm{C}\right)$.

the values of each group (combination of temperature and irradiance), the characteristic curves $P$ - $I$ have been obtained and their MPPs have been found. For example, Figure 11 shows a characteristic curve $P-I$ for each irradiance, all of them at a constant temperature of $25^{\circ} \mathrm{C}$. With all the MPP points of Figure 11, a curve of Figure 12 has been created using interpolation, specifically the curve corresponding to $25^{\circ} \mathrm{C}$. That is, each curve of Figure 12 contains the MPPs for all irradiances (implicitly as one moves in the abscissa axis) of a given temperature, expressing it as $I_{\mathrm{MPP}}=f(G)$. With the triplets $\left(I_{\mathrm{MPP}}, P_{\mathrm{MPP}}\right.$, and $\left.T\right)$, an interpolation is carried out in order to obtain a function $I_{\mathrm{MPP}}=f\left(P_{\mathrm{MPP}}, T\right)$ that gives the value of the current at the MPP for given values of power 


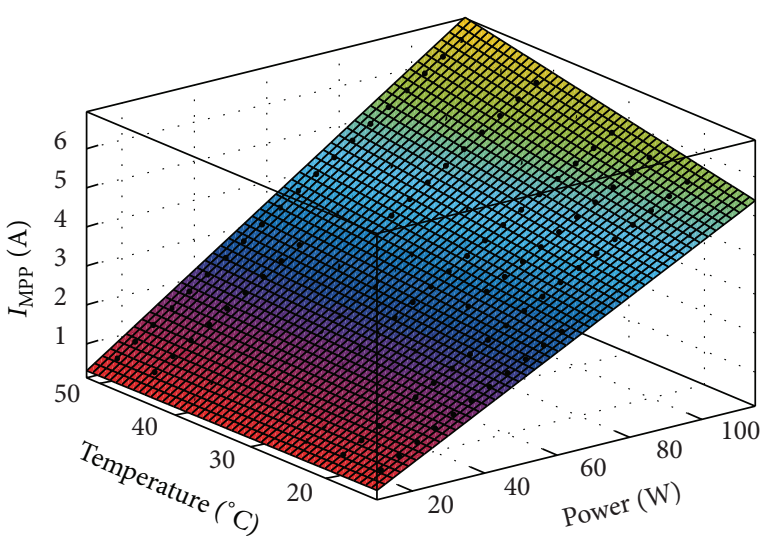

FIgURE 13: $P-T-I$ characteristic surface of the MPPs.

and temperature. Finally, Figure 13 is created interpolating the curves shown in Figure 12 and it gives us the reference current for the maximum power point at given temperature and irradiance.

With these values, we trained an ANN to learn the function $I_{\mathrm{MPP}}=F\left(P_{\mathrm{MPP}}, T\right)$. The process to obtain the neural network is similar to that followed when learning the photovoltaic module model carried out in Section 3.2, taking into account that in this case it has two inputs $\left(P_{\mathrm{MPP}}, T\right)$ and one output $\left(I_{\mathrm{MPP}}\right.$ or $\left.I_{\mathrm{REF}}\right)$.

We obtained the maximum power points data to carry out the ANN training calculating them for power values ranging from 15 to $110 \mathrm{~W}$ with step of $5 \mathrm{~W}$, while for temperature values range from from 15 to $50^{\circ} \mathrm{C}$ with step of $5^{\circ} \mathrm{C}$. In this way, we got a set of 160 triplets $\left(P_{\mathrm{MPP}}, T\right.$, and $\left.I_{\mathrm{MPP}}\right)$, of which 112 samples were used for training $(70 \%), 24$ for validation (15\%), and the remaining 24 for the test (15\%).

An ANN of four hidden nodes was trained with backpropagation Levenberg-Marquardt algorithm. After 489 iterations, a network with a Mean Squared Error (MSE) of 2.036 $\times 10^{-3} \mathrm{~A}$ and a training correlation coefficient $R=0.99992$ was achieved as shown in Figure 14, while its test correlation coefficient was $R=0.99986$, as shown in Figure 15. So, we can state that the ANN has learned properly the behavior of the sliding mode controller.

4.3. Stability Demonstration. As we have seen in the previous section, the neural network will help us determine currents of reference required by the system at all times; then the converter will force the photovoltaic system to work with the reference value obtained and thus in the area of the maximum power

$$
\begin{aligned}
& S=e=I_{\mathrm{REF}}-I_{p}, \\
& u=\int_{0}^{t} k \cdot \operatorname{sign}(S(t)) d t .
\end{aligned}
$$

In order to limit the control signal of operating range for the duty cycle of our DC/DC converter, the integral of the control signal is limited between 0.1 and 0.9 .

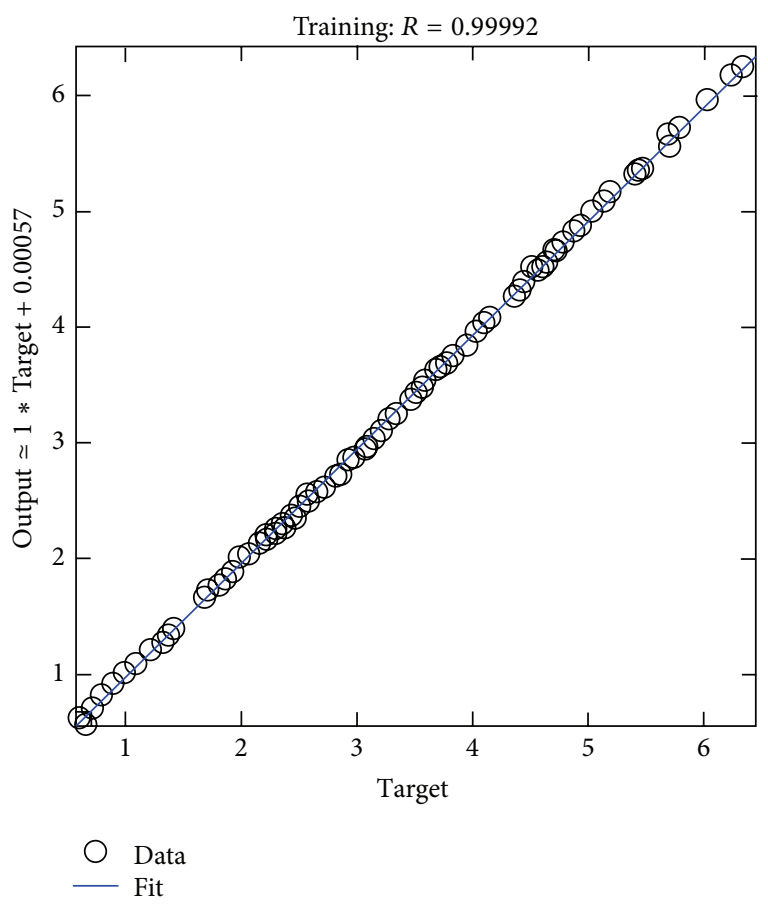

FIgURE 14: Train correlation coefficient.

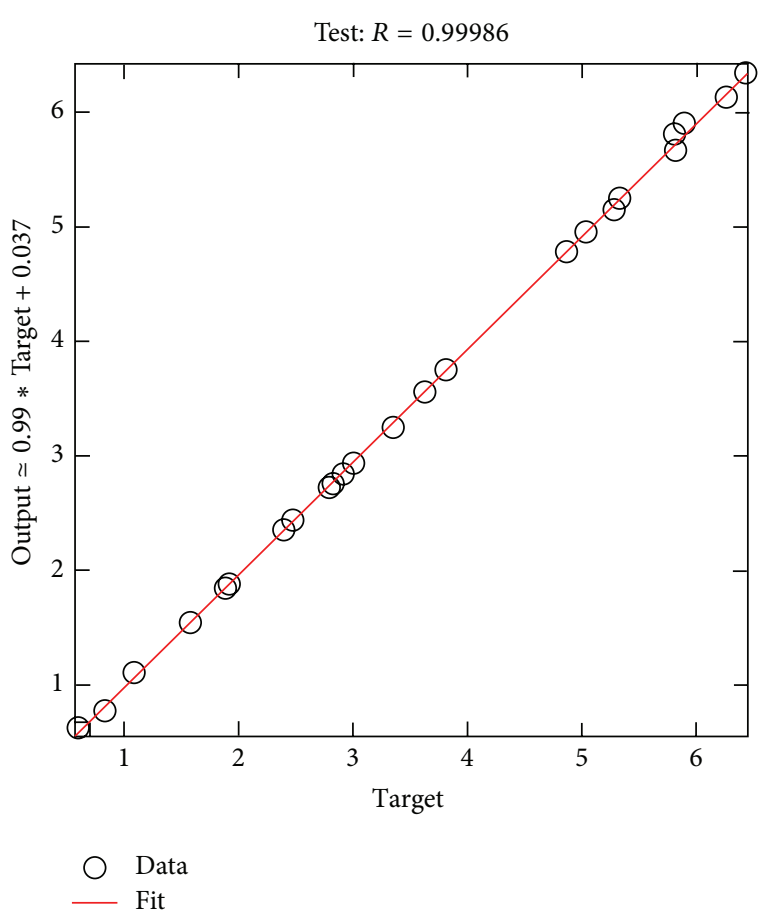

FIGURE 15: Test correlation coefficient.

The demonstration of stability of the proposed controller is based on the theory of Lyapunov stability. For this purpose a Lyapunov function is defined by

$$
V=\frac{1}{2} S^{2}>0
$$




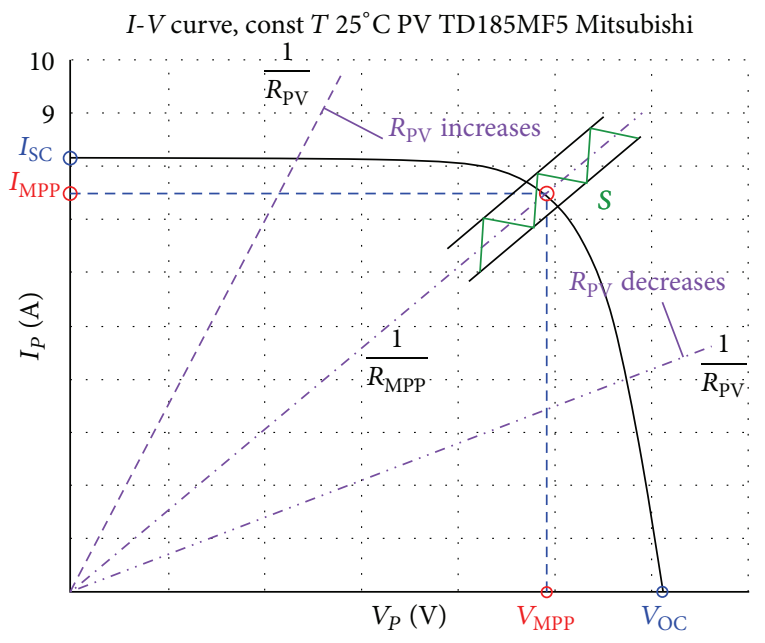

FIGURE 16: Behavior of the $R_{\mathrm{PV}}$ related to the characteristic curve.

whose derivative with respect to time is given by

$$
\dot{V}=S \frac{d S}{d t}=S \cdot \dot{S}<0 .
$$

Taking into account the expression of

$$
\begin{aligned}
& S=e=I_{\mathrm{MPP}}^{*}-I_{\mathrm{PV}} \\
& \dot{S}=\dot{e}=-\dot{I}_{\mathrm{PV}}
\end{aligned}
$$

and using Lyapunov stability theory, it can be shown that when $\dot{V}<0$, the value of $S$ tends to zero and therefore the system state converges to MPP.

When $S>0$. It means that the reference current provided by the reference generator is larger than the current provided by the module. For this reason and to make the tracking error be zero $(S=0), I_{\mathrm{PV}}$ has to increase and therefore, the $V_{\mathrm{PV}}$ must decrease. For this purpose, $R_{\mathrm{PV}}$ has to decrease, which is achieved increasing the duty cycle $(\delta)$ as we can deduce from (6). In Figure 16, we see the behavior of the $R_{\mathrm{PV}}$ magnitude.

We check stability because if $I_{\mathrm{PV}}$ increases, $\dot{S}$ will be negative and also the product $S \cdot \dot{S}<0$, which implies that the system is stable and converges to the maximum power point.

When $S<0$. Using the same procedure, we have $I_{\mathrm{REF}}<I_{P}$ and then $\dot{S}$ is positive and the product $S \cdot \dot{S}<0$, which implies that the system is stable and converges to the maximum power point.

For this reason and to make the tracking error be zero $(S=0), I_{\mathrm{PV}}$ current has to decrease and therefore $V_{\mathrm{PV}}$ must increase. For this purpose, $R_{\mathrm{PV}}$ has to increase, which is achieved by decreasing the duty cycle $(\delta)$, as we can deduce from (6).

\section{Results}

In this section, we present our results divided into two subsections attending to their nature:
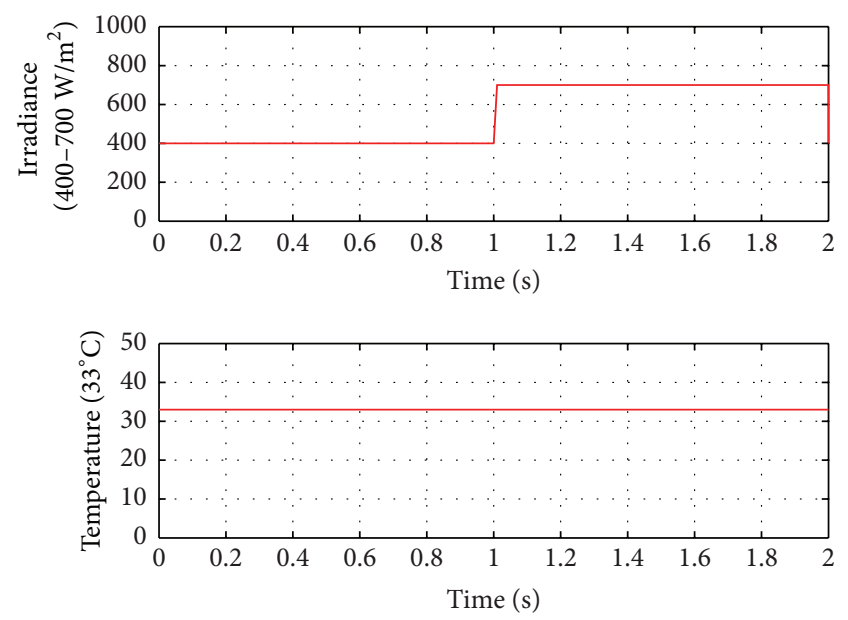

FIgUre 17: Temperature (constant) and irradiance (step) input values.

(a) Simulation Results. They are obtained using the photovoltaic module model in the MathWorks Matlab/Simulink environment. Due to the ease to change the weather dependent parameters, we tested the operation of the controller when abrupt changes in irradiance and temperature.

(b) Experimental Results. They are obtained operating on the actual system making real measurements. In this case, we present the operation of the controller when there are load variations.

5.1. Simulation Results. The first test carried out in order to test the performance of the controller analyzes its response when there are sudden irradiance changes. As shown in Figure 17, we have used a constant temperature of $33^{\circ} \mathrm{C}$ and an irradiance step from 400 to $700 \mathrm{~W} / \mathrm{m}^{2}$ after two seconds of simulation.

As we can see in Figure 18, the obtained power at the output of the converter (blue line), that is, the power absorbed by the load, follows the power value of the output of the module (red line). This shows that the controller has a good performance when dealing with irradiance changes.

The second test is devoted to study the behavior of the controller when there are sudden temperature changes. In this case, the irradiance is constant $\left(800 \mathrm{~W} / \mathrm{m}^{2}\right)$, while the temperature changes suddenly from 10 to $45^{\circ} \mathrm{C}$, as shown in Figure 19.

In this case, we also can see in Figure 20 that the converter output power (blue line) again follows the power value of the output of the module (red line). So we can state that the converter has a good performance when dealing with temperature changes.

5.2. Experimental Results. In this section, we will analyze the behavior of the proposed controller under real conditions.

In order to carry out the experiments, we used a realtime digital sign processor (DSP) model dSPACE DSP1104 integrated with MathWorks Matlab/Simulink through its 


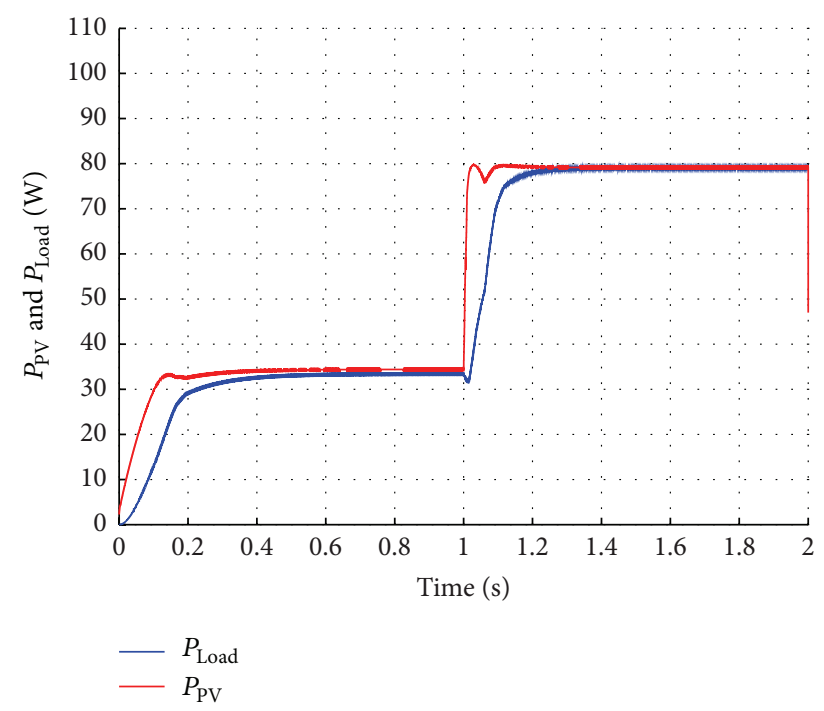

FIGURE 18: Power response when sudden irradiance changes.
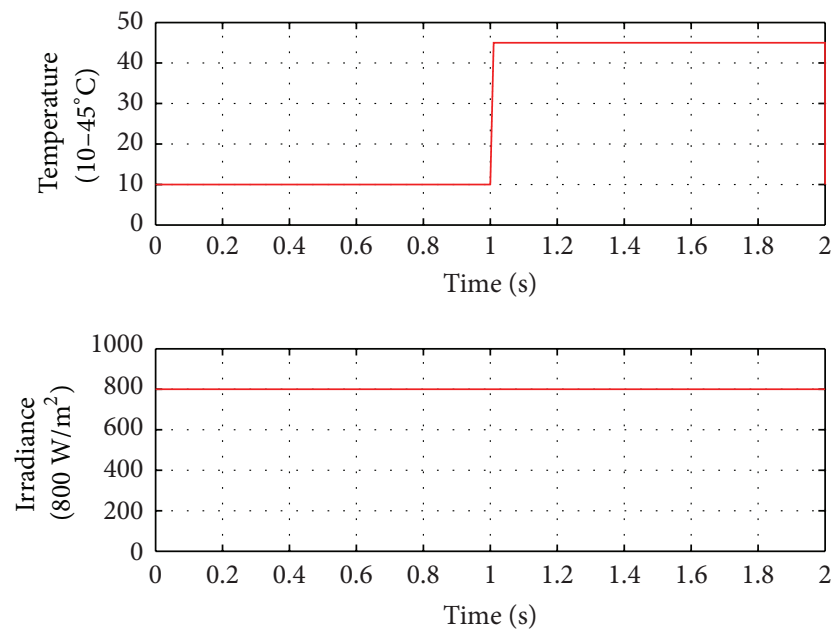

FIgURE 19: Temperature (step) and irradiance (constant) input values.

toolbox for real-time work and Real-Time Interface (RTI). This is widely used in industry and research because it reduces the time gap between the simulation and the development of real implementation, profiting from its capability to simulate failures and to analyze the behavior of the real system.

The installation in which the experiments have been carried out consists of the Mitsubishi PV-TD185MF5 photovoltaic module, a boost converter, a DSP model dSPACE DSP1104, a variable load, and a personal computer for data storage, as shown in the schematics of Figure 21, while Figures 22(a) and 22(b) show the actual installation. The used boost converter has been designed and manufactured by the TEP 192 Research Group of the University of Huelva (Spain), and its specifications are shown in Table 2.

The communication between the DSP and the computer has been done using the ControlDesk Next Generation 5.1

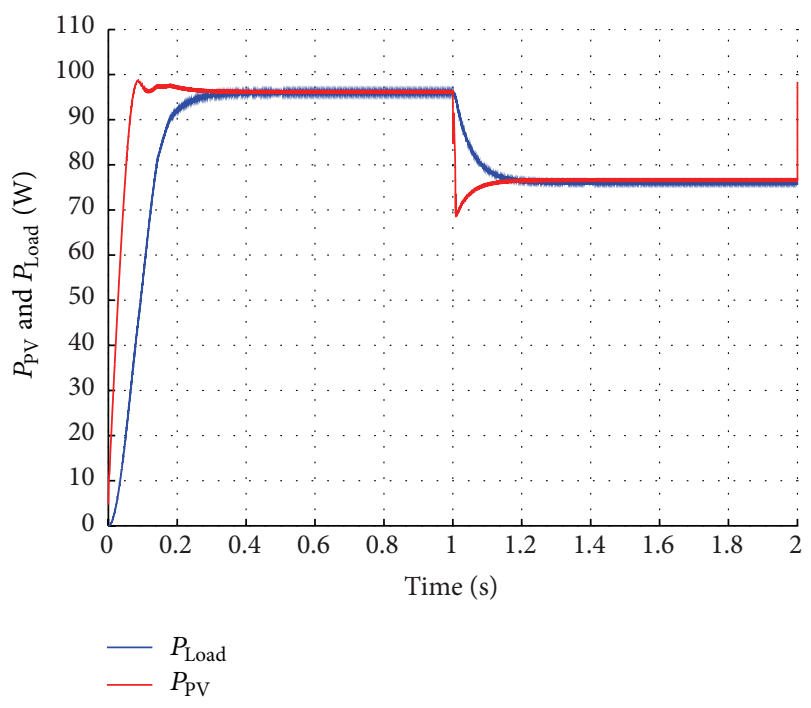

FIgURE 20: Power response when sudden temperature changes.

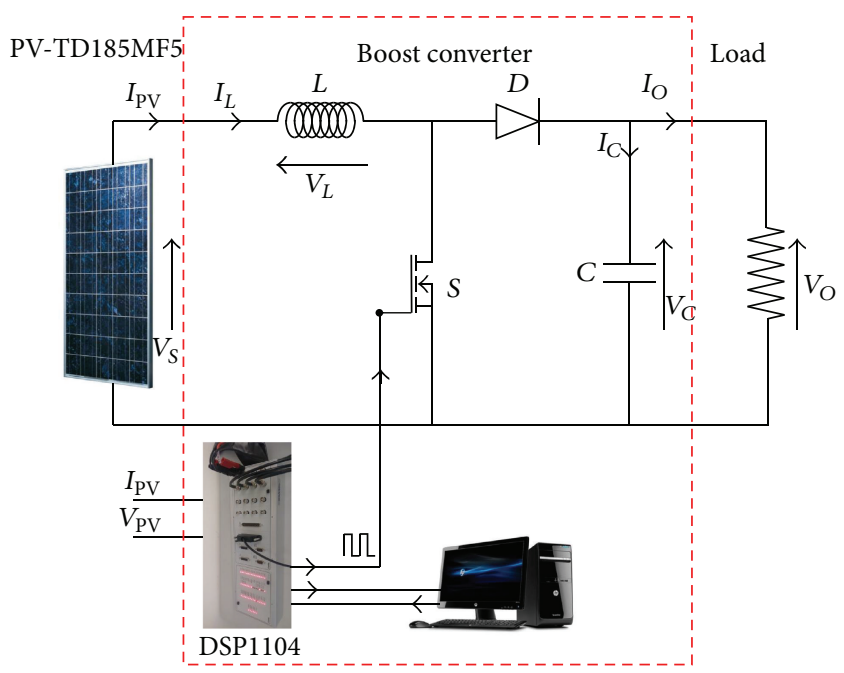

FIGURE 21: System block diagram.

TABLE 2: Boost converter parameters.

\begin{tabular}{lcc}
\hline \multicolumn{2}{c}{ Boost converter } \\
\hline Schottky & 2x MURF1560GT & $600 \mathrm{~V}, 15 \mathrm{~A}, 0.4 \mathrm{~V}$ to $10 \mathrm{~A} / 150^{\circ} \mathrm{C}$ \\
IGBT & 1x HGT40N60B3 & $600 \mathrm{~V}, 40 \mathrm{~A}, 1.5 \mathrm{~V}$ to $150^{\circ} \mathrm{C}$ \\
$L$ & $6 x$ PCV-2-564-08 & $560 \mu \mathrm{H}, 7 \mathrm{~A}, 42 \mathrm{~m} \Omega$ \\
$C$ & $2 x$ TK Series & $1500 \mu \mathrm{F}, 250 \mathrm{~V}$ \\
\hline
\end{tabular}

software, which allows display on the screen and manipulating real-time system variables through a graphical user interface.

Once the experimental setup is fixed, the first step is to find out which is the maximum power point for the actual conditions in which the system is working. For this purpose, the variable load is connected directly to the photovoltaic module and its value is varied from its minimum to its maximum value $(0-47 \Omega)$ gathering pairs of $(P, I)$ points 


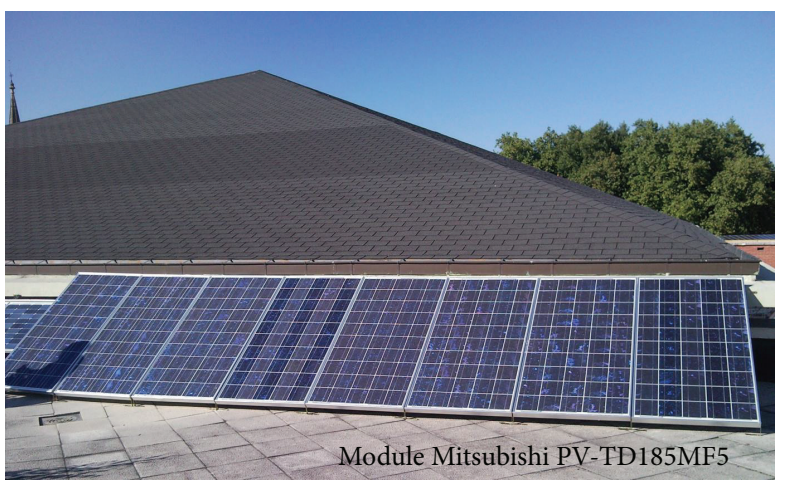

(a)

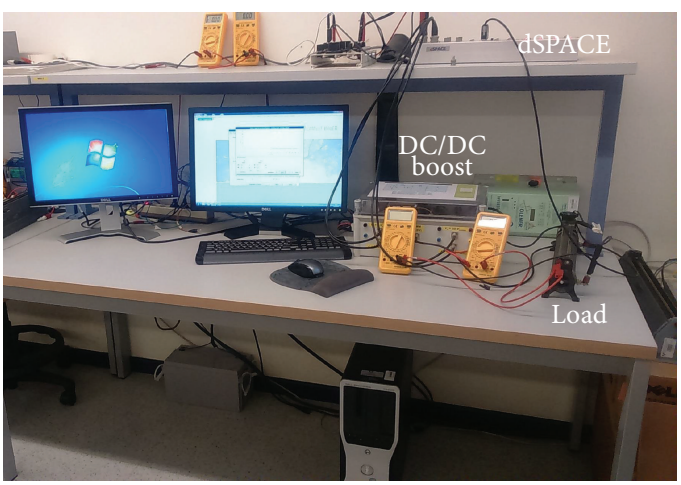

(b)

Figure 22: Picture of the actual installation.

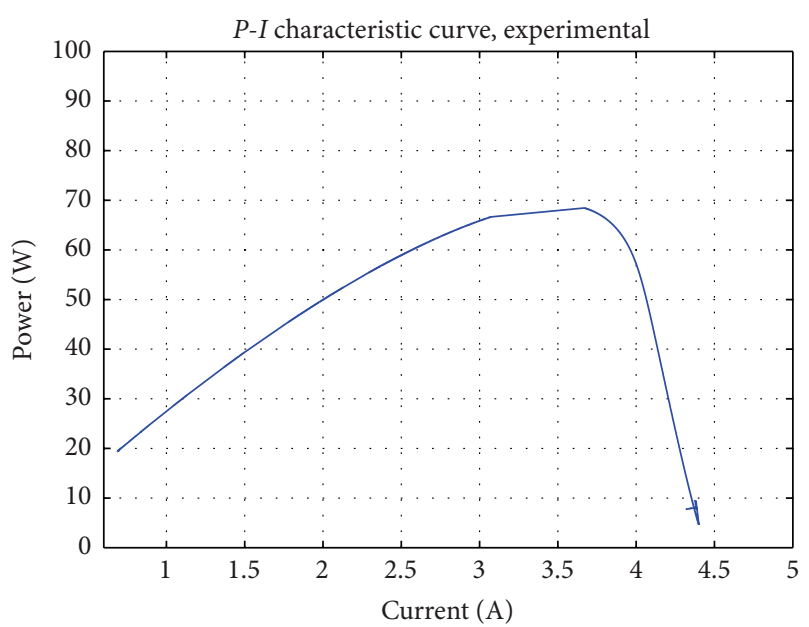

Figure 23: $P$-I characteristic curve from experimental data.

with which the $P-I$ characteristic curve is obtained (see Figure 23) and locates the maximum power point. In this real experiment case, that point corresponded to a current $I_{\mathrm{MPP}}$ of 3.6 A and a $P_{\text {MPP }}$ power of approximately $68 \mathrm{~W}$.

Now that the value that the converter should follow is known, the installation is prepared to make the measurements.

The experiment is to vary the load and check that the power supplied to the load by the converter follows the power given by the photovoltaic module, in such a way that although the load varies, the converter continues operating at the maximum power point under the existing irradiance and temperature conditions at each moment.

During the experiment the load was manually varied from $23 \Omega$ to $39 \Omega$, so the change is not immediate as can be seen in Figure 24 because the load needs some time to move from one value to other.

During the experiment, the temperature (blue line) and the irradiance (red line) are quite stable due to its short duration, remaining on approximate values of $33^{\circ} \mathrm{C}$ and $635 \mathrm{~W} / \mathrm{m}^{2}$ as can be seen in Figure 25 .

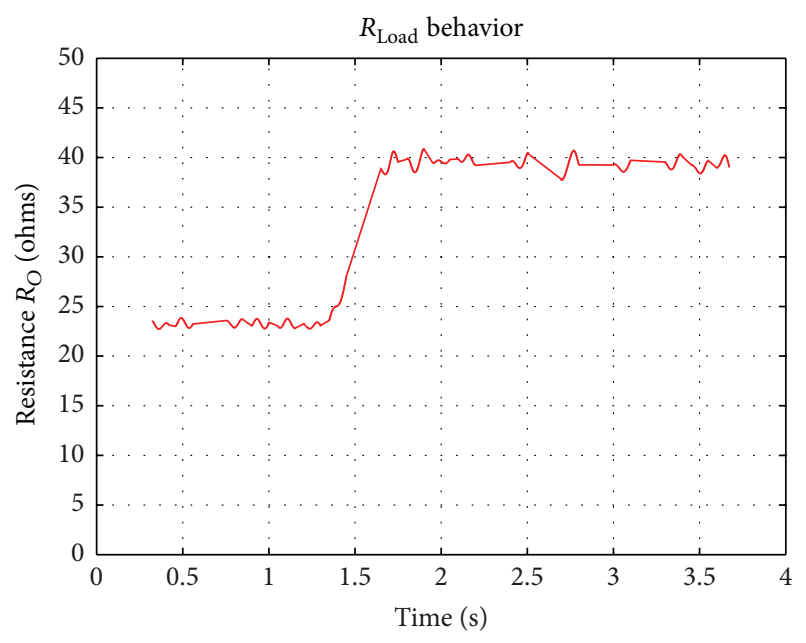

FIgURE 24: Behavior of the load resistance $R_{\text {Load }}$.

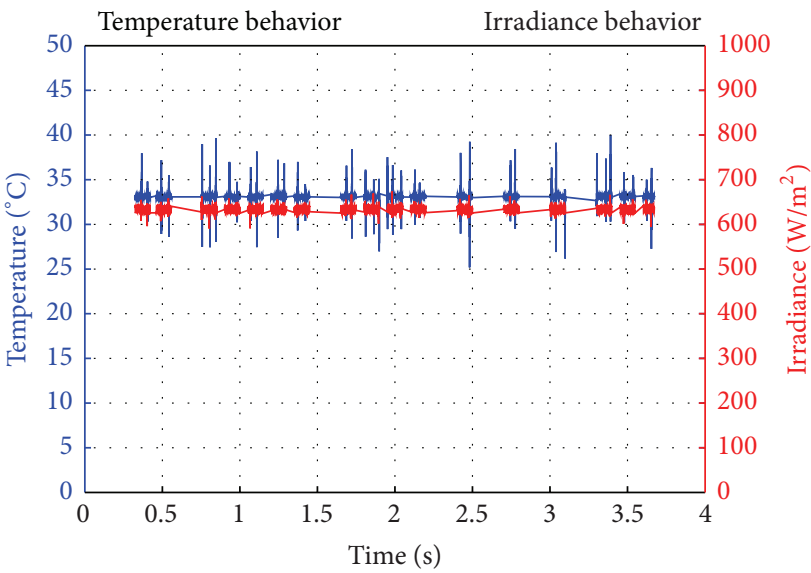

Figure 25: Behavior of temperature $(T)$ and irradiance $(G)$.

Figure 26 shows the behavior of the power at the output of the converter (or in load) and at the output of the photovoltaic module which are compared, being very close and remaining around a mean value of $68.5 \mathrm{~W}$. This value is approximately 


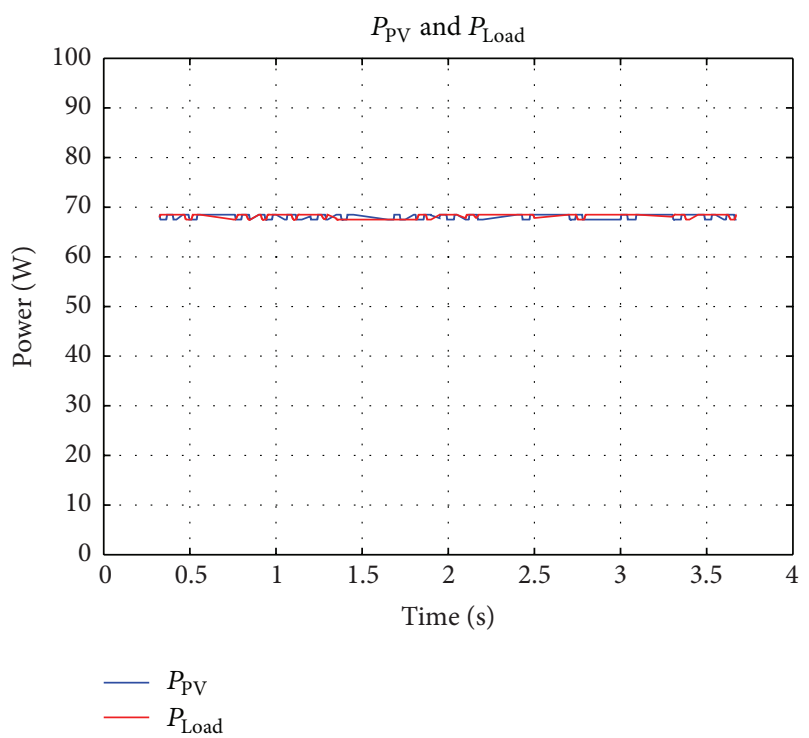

Figure 26: $P_{\mathrm{PV}}$ behavior versus $P_{\text {Load }}$.

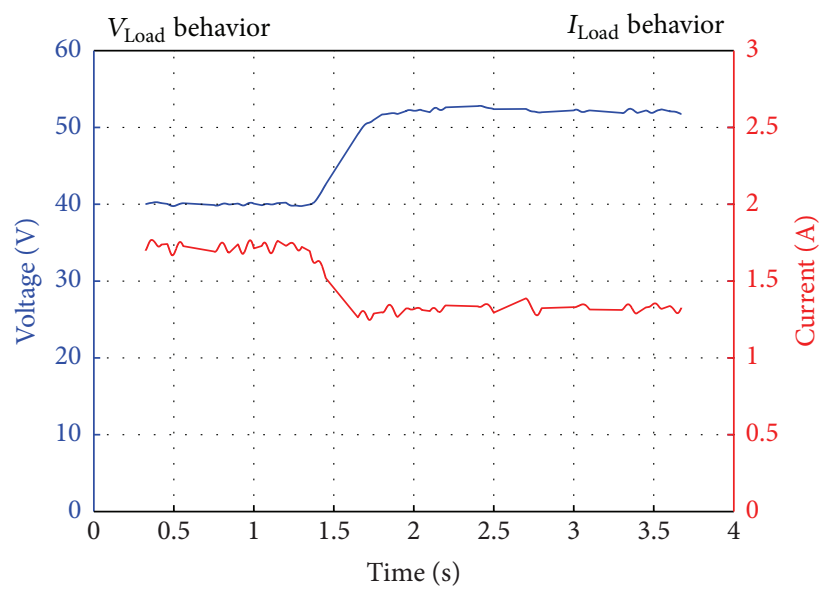

FIGURE 27: Behavior of load voltage $V_{\text {Load }}$ and load current $I_{\text {Load }}$.

the same that the MPP provided the P-I characteristic curve as shown in Figure 23.

Finally, the voltage and current values in the load can be seen in Figure 27. It must be noted that the change of the load value implies a value change in these two variables, the product of both of them being the value of the power given to the load, which should be kept constant (as seen in Figure 27).

After this real experiment, we can state that the designed converter has also a good performance when the load value is changed.

\section{Conclusions}

In this paper, we have addressed one of the more outstanding problems when dealing with photovoltaic modules, that is, the maximum power point tracking problem when a boost $\mathrm{DC} / \mathrm{DC}$ converter is used.
In the first part of the paper, we have given a short background on some key topics regarding the paper, as the basic description of a photovoltaic generator and its characteristic curves, boost DC/DC converters, artificial neuronal networks, and sliding mode control.

Later, we have detailed all the components of a real photovoltaic installation placed at the Faculty of Engineering Vitoria-Gasteiz (Basque Country University, Spain). That installation has been used to acquire data about the real operation of the Mitsubishi Electric PV-TD185MF5 185 W photovoltaic module. We have explained how the data have been gathered and the process used to train an artificial neural network to learn the behavior of the real module, obtaining a very accurate model with $\mathrm{MSE}=0.062 \mathrm{~A}$ and $R=0.991$ when tested with a new dataset. So, the first finding of this paper is a very accurate neuronal model obtained from real data.

Once we have got a validated model of the photovoltaic module, which allows us to make simulations, we design the sliding mode controller. The controller generates a pulse signal to control the boost DC/DC converter, but in turn, it needs a reference signal. In this work, we have used as reference a current signal, more specifically, the current at which the module gives maximum power for a given temperature and irradiance conditions. That information was obtained from the real gathered data and since we are dealing with a sliding mode controller, it has represented as a sliding surface.

Finally, we have carried out several tests in order to validate the controller and its robustness when there are sudden changes in temperature, irradiance, and load. Simulated and real tests have shown that the controller that provides a good overall performance guaranteeing that the power in the output of the converter is very close to the power of the photovoltaic module output, this one being the second main contribution of the paper.

\section{Competing Interests}

The authors declare that they have no competing interests.

\section{Acknowledgments}

The authors are very grateful to the UPV/EHU for its support through Projects GIU13/41 and UFI11/07.

\section{References}

[1] United Nations Climate Change Conference, Paris, France, 2015, http://www.cop21.gouv.fr/en/.

[2] T. Logeswaran and A. SenthilKumar, "A review of maximum power point tracking algorithms for photovoltaic systems under uniform and non-uniform irradiances," Energy Procedia, vol. 54, pp. 228-235, 2014.

[3] V. Salas, E. Olías, A. Barrado, and A. Lázaro, "Review of the maximum power point tracking algorithms for stand-alone photovoltaic systems," Solar Energy Materials and Solar Cells, vol. 90, no. 11, pp. 1555-1578, 2006.

[4] A. H. Alqahtani and V. I. Utkin, "Self-optimization of photovoltaic system power generation based on sliding mode control," 
in Proceedings of the 38th Annual Conference on IEEE Industrial Electronics Society (IECON '12), pp. 3468-3474, IEEE, Montreal, Canada, October 2012.

[5] Y. Levron and D. Shmilovitz, "Maximum power point tracking employing sliding mode control," IEEE Transactions on Circuits and Systems I: Regular Papers, vol. 60, no. 3, pp. 724-732, 2013.

[6] J. J. Slotine and W. Li, Applied Nonlinear Control, Prentice-Hall, Englewood Cliffs, NJ, USA, 1991.

[7] A. Cid-Pastor, L. Martinez-Salamero, A. El Aroudi, R. Giral, J. Calvente, and R. Leyva, "Synthesis of loss-free resistors based on sliding-mode control and its applications in power processing," Control Engineering Practice, vol. 21, no. 5, pp. 689-699, 2013.

[8] F. Zhang, J. Maddy, G. Premier, and A. Guwy, "Novel current sensing photovoltaic maximum power point tracking based on sliding mode control strategy," Solar Energy, vol. 118, pp. 80-86, 2015.

[9] A. Luque and S. Hegedus, Eds., Handbook of Photovoltaic Science and Engineering, John Wiley \& Sons, 2011.

[10] M. Wolf and H. Rauschenbach, "Series resistance effects on solar cell measurements," Advanced Energy Conversion, vol. 3, no. 2, pp. 455-479, 1963.

[11] D. S. H. Chan and J. C. H. Phang, "Analytical methods for the extraction of solar-cell single- and double-diode model parameters from I-V characteristics," IEEE Transactions on Electron Devices, vol. 34, no. 2, pp. 286-293, 1987.

[12] J. A. Gow and C. D. Manning, "Development of a photovoltaic array model for use in power-electronics simulation studies," IEE Proceedings-Electric Power Applications, vol. 146, no. 2, pp. 193-200, 1999.

[13] M. R. AlRashidi, K. M. El-Naggar, and M. F. AlHajri, "Parameters estimation of double diode solar cell model," International Journal of Electrical, Computer, Energetic, Electronic and Communication Engineering, vol. 7, no. 2, pp. 118-121, 2013.

[14] A. M. Humada, M. Hojabri, S. Mekhilef, and H. M. Hamada, "Solar cell parameters extraction based on single and doublediode models: a review," Renewable and Sustainable Energy Reviews, vol. 56, pp. 494-509, 2016.

[15] M. G. Villalva, J. R. Gazoli, and E. Ruppert Filho, "Modeling and circuit-based simulation of photovoltaic arrays," in Proceedings of the Brazilian Power Electronics Conference (COBEP '09), pp. 1244-1254, Bonito-Mato Grosso do Sul, Brazil, October 2009.

[16] W. De Soto, S. A. Klein, and W. A. Beckman, "Improvement and validation of a model for photovoltaic array performance," Solar Energy, vol. 80, no. 1, pp. 78-88, 2006.

[17] F. M. González-Longatt, "Model of photovoltaic module in Matlab," in 2do Congreso Iberoamericano de Estudiantes de Ingeniería Eléctrica, Electrónica y Computación (II CIBELEC '05), vol. 2005, pp. 1-5, Puerto la Cruz, Venezuela, 2005.

[18] G. Walker, "Evaluating MPPT converter topologies using a MATLAB PV model," Journal of Electrical and Electronics Engineering, vol. 21, no. 1, pp. 49-55, 2001.

[19] A. Oi, Design and simulation of photovoltaic water pumping system [Ph.D. thesis], California Polytechnic State University, San Luis Obispo, Calif, USA, 2005.

[20] H. L. Tsai, C. S. Tu, and Y. J. Su, "Development of generalized photovoltaic model using MATLAB/SIMULINK," in Proceedings of the World Congress on Engineering and Computer Science, vol. 2008, pp. 1-6, October 2008.

[21] G. Bayrak and M. Cebeci, "Grid connected fuel cell and PV hybrid power generating system design with Matlab Simulink," International Journal of Hydrogen Energy, vol. 39, no. 16, pp. 8803-8812, 2014.
[22] J. A. Ramos-Hernanz, J. M. Lopez-Guede, I. Z. Belver et al., "Modelling of a photovoltaic panel based on their actual measurements," International Journal on Technical and Physical Problems of Engineering, vol. 6, no. 4, pp. 37-41, 2014.

[23] M. Ameziane, B. Sefriti, J. Boumhidi, and K. Slaoui, "Neural network sliding mode control for a photovoltaic pumping system," Journal of Electrical Systems, vol. 9, no. 3, pp. 380-391, 2013.

[24] S. Kalogirou and A. Sencan, "Artificial intelligence techniques in solar energy applications," in Solar Collectors and Panels, Theory and Applications, R. Manyala, Ed., chapter 15, pp. 315340, InTech, Rijeka, Croatia, 2010.

[25] F. Almonacid, L. Hontoria, J. Aguilera, and G. Nofuentes, "Una nueva aproximación para la caracterización de módulos fotovoltaicos basada en redes reuronales," Boletín del Instituto de Estudios Giennenses 192, 2005.

[26] F. Almonacid, C. Rus, L. Hontoria, and F. J. Muñoz, "Characterisation of PV CIS module by artificial neural networks. A comparative study with other methods," Renewable Energy, vol. 35, no. 5, pp. 973-980, 2010.

[27] J. M. Lopez-Guede, J. A. Ramos-Hernanz, E. Zulueta, and U. Fernandez-Gamiz, "Towards a systematic neural network based modelization of photovoltaic modules," in Proceedings of the $3 \mathrm{rd}$ European Conference on Renewable Energy Systems (ECRES '15), E. Kurt, Ed., October 2015.

[28] F. Bonanno, G. Capizzi, G. Graditi, C. Napoli, and G. M. Tina, "A radial basis function neural network based approach for the electrical characteristics estimation of a photovoltaic module," Applied Energy, vol. 97, pp. 956-961, 2012. 

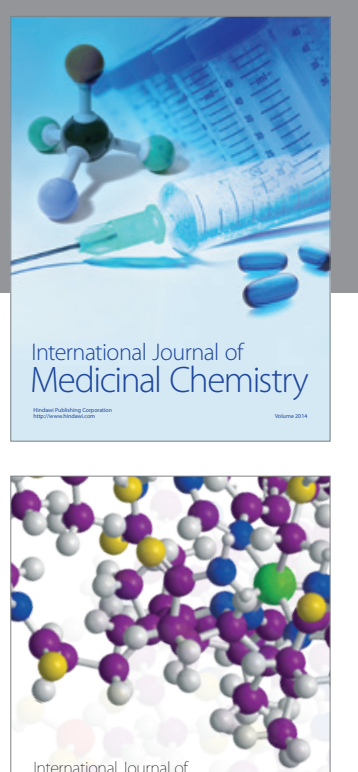

Carbohydrate Chemistry

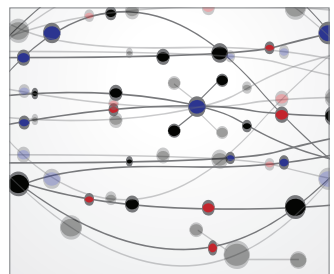

The Scientific World Journal
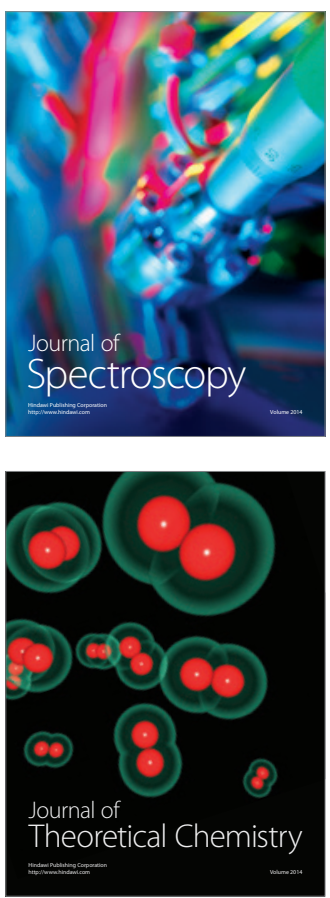
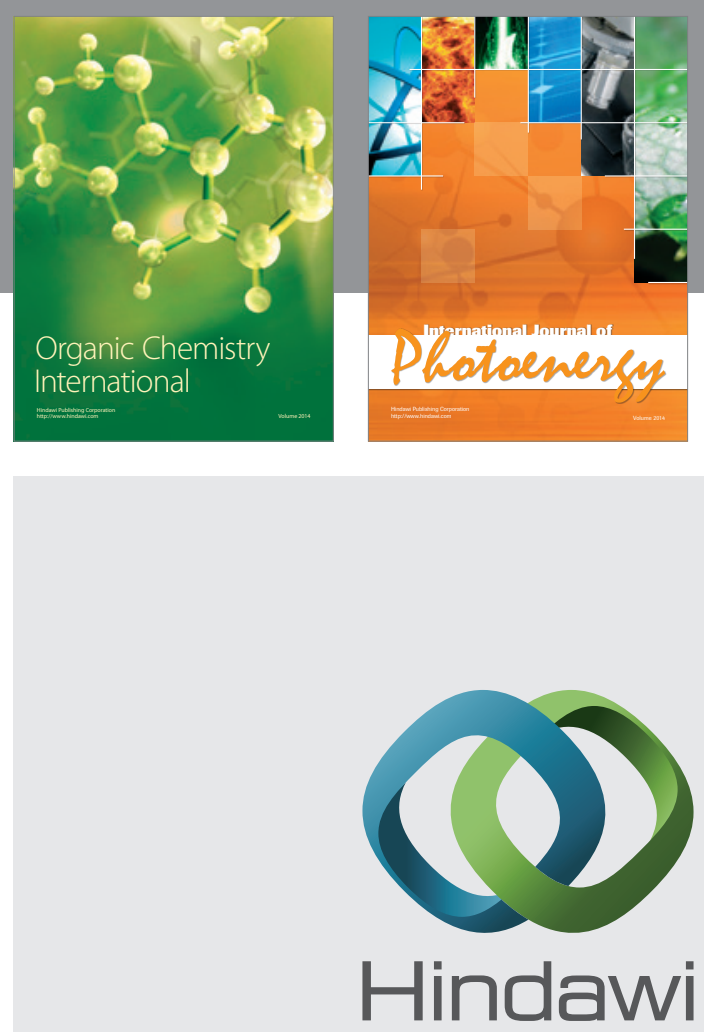

Submit your manuscripts at

http://www.hindawi.com

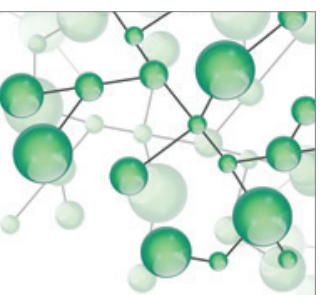

International Journal of

Inorganic Chemistry

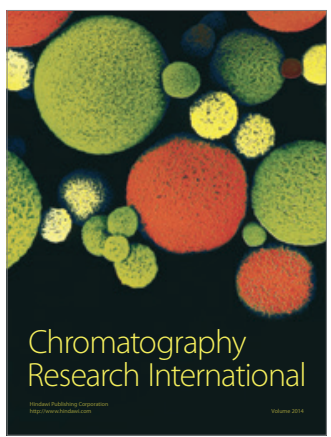

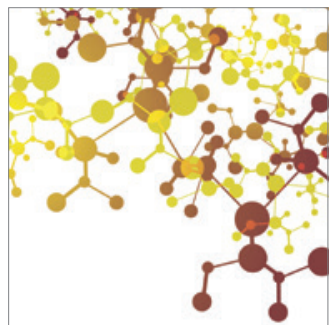

Applied Chemistry
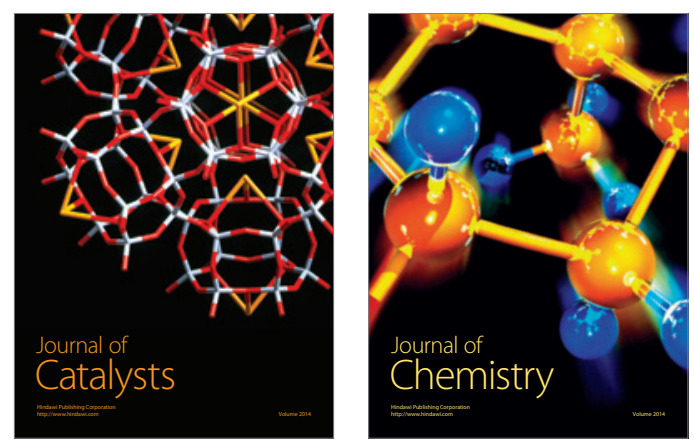
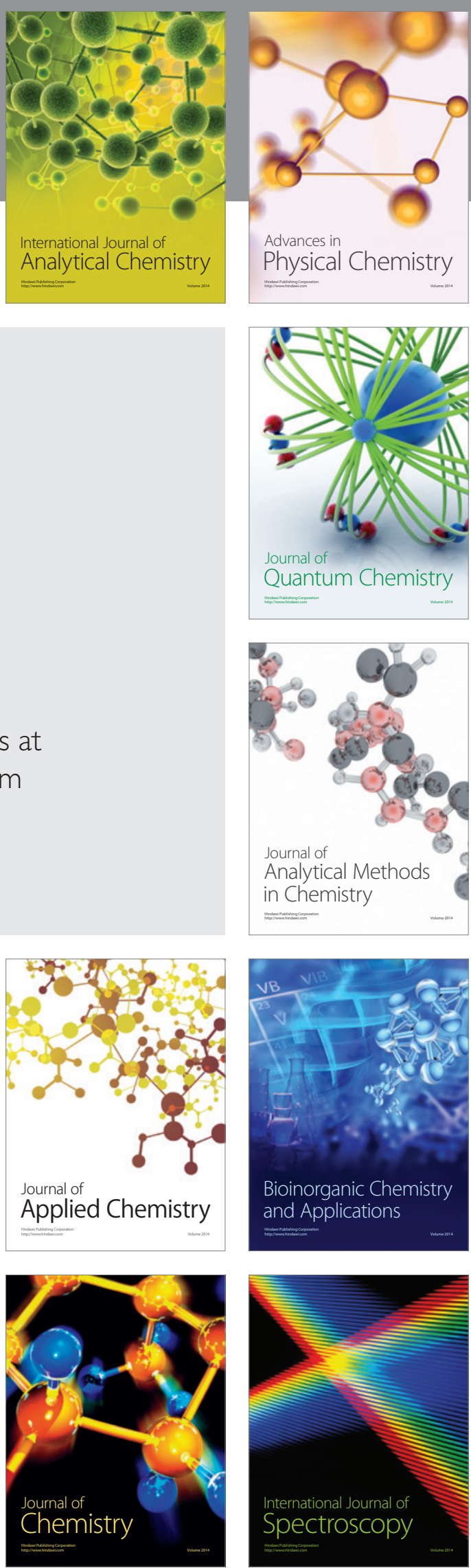